\title{
The North Atlantic Nutrient Stream
}

\author{
J. L. Pelegril ${ }^{1}$, G. T. Csanady ${ }^{2}$ and A. Martins ${ }^{2}$ \\ 'Facultad de Ciencias del Mar, Universidad de Las Palmas de Gran Canaria, Canary Islands, Spain \\ ${ }^{2}$ Center for Coastal Physical Oceanography, Old Dominion University, Virginia
}

(Received 1 April 1995; in revised form 30 August 1995; accepted 4 November 1995)

Western boundary currents are the locus of intense nutrient transport, or nutrient streams. The largest fraction of this transport takes place in the upper-thermocline layers, between the surface layers (where speed reaches a maximum) and the nutrient bearing strata of the subtropical gyres (where nutrient concentration is maximum). The core of the nutrient stream of the North Atlantic subtropical gyre is located slightly offshore the Gulf Stream, its density coordinate centered on the 26.5-27.3 $\sigma_{\theta}$-band, approximately constant along the axis of the stream. During late spring and summer the nutrient stream reaches the surface seasonal mixed layer at the outcropping of this isopycnal band. We argue that this must be a principal factor sustaining the seasonal high productivity of the subpolar North Atlantic Ocean. Additionally, we investigate the possibility of intermittent shearinduced diapycnal mixing in the upper-thermocline layers of the Gulf Stream, induced by frontogenesis taking place during some phase of the meanders. Here we illustrate that diapycnal mixing has a maximum at the location of the nutrient stream, being associated to observed nutrient anomalies. We suggest that diapyenal mixing associated to the passage of steep meanders brings nutrients from the nutrient stream to the shallow photic layers, and sustains intermittent (day-toweek) patchy $(10-100 \mathrm{~km})$ productivity over the stream itself.

\section{Introduction}

The first substantial effort to model the thermocline distribution of oxygen and nutrients in the Atlantic Ocean is due to Riley (1951). He employed a simple diffusive-advective type model (allowing for biological rates of change), which used the geostrophic thermocline circulation pattern as deduced from the salinity and temperature data available at that time. His early, and rather correct, view was that the observed distributions are the result of advective-diffusive physical processes combined with biological processes such as oxygen consumption, and nutrient uptake and regeneration. According to Reid (1981), if it had not been that Riley's analysis came just after Munk's (1950) work on western boundary currents, "it might have estimulated a more thorough investigation, even with those limited data, of the variation of flow patterns with depth that might have been carried out concurrently with the studies of total transport". The fact is that this type of approach did not get restarted until last decade, with the works of Bolin et al. (1983), Schlitzer $(1988,1989)$ and Thiele and Sarmiento (1990).

Riley's (1951) insight went to the extent of showing his results interpolated on isopycnal surfaces. This was on the line of Montgomery's $(1937,1938)$ isopycnic view of circulation which, however, was not followed by the scientific community until the mid sixties (Kirwan, 1963; Reid, 1965; Tsuchiya, 1968). One of the most striking features arising from Riley's study is the presence of nutrient-rich and oxygen-poor layers in the mid-thermocline, approximately 
between the isopycnals $\sigma_{t}=26.8$ and 27.5. These layers have been called the "nutrient bearing stratum" of the North Atlantic by Csanady (1990) and Pelegri and Csanady (1991). Recent data reveal the extent and permanence of the nutrient bearing stratum. For example, the transatlantic sections in Roemmich and Wunsch (1985) and Rintoul and Wunsch (1991) show how this stratum extends zonally over the whole North Atlantic Ocean. Its meridional extent, as seen in Kawase and Sarmiento (1985) and Reid (1994) isopycnal maps, is also large.

In the late 1970s enough empirical knowledge was available to describe the pattern of thermocline circulation (e.g. Worthington, 1976; Reid, 1981). The relation between thermocline circulation and the outcropping of the isopycnal surfaces became clear in Sarmiento et al.'s (1982) isopycnic analysis of the North Atlantic tritium distribution. The upper-thermocline layers show large southwest-northeast gradients, which reflect the input of high tritium concentration waters at the outcropping regions, where Ekman pumping velocities are negative (Leetma and Bunker, 1978). Kawase and Sarmiento (1985) presented nutrient isopycnic maps with opposite gradients, suggesting that the thermocline waters of the subtropical gyre are enriched in nutrients during their southward and westward trip. Sarmiento (1983) and Jenkins (1987) also showed that downward Ekman pumping was far too small to account for the water flux along the thermocline layers. They suggested that other exchange processes at the outcrop regions, such as mixing and convective overturning, should be dominant. Simultaneous with this developing observational picture, came also a better understanding of the physical mechanisms that cause it. Stommel (1979) was the first to combine Sverdrup dynamics with Montgomery's (1937) isopycnic approach, with thermocline waters originating in regions of negative Ekman pumping. Recent modeling efforts, based on Luyten et al. (1983) and Rhines and Young (1982) works, have incorporated other effects such as diabatic cooling/heating (e.g. Luyten and Stommel, 1986; Veronis, 1988; Nurser and Marshall, 1991).

Despite the improved understanding of the thermocline problem, the western end of these theories remains unclear. Circulation maps for the North Atlantic close the water transport balance through western boundary currents at all isopycnal surfaces, but do not indicate how this takes place. Rossby (1936) pioneered the idea of epipycnal water input into western boundary currents, based on the continuity of oxygen and nutrient distributions. In the Slope Sea and at the edge of the continental shelf the nutrient bearing stratum approaches the sea surface and mixing is enhanced. As Redfield (1936) originally suggested, this is the source of nutrients for the highly productive continental shelf of the United States (Yentsch, 1974; Yoder et al., 1983; Brown et al., 1984; Atkinson et al., 1987). The layers involved in this epipycnal cross-stream exchange correspond to the upper thermocline $\left(26.8<\sigma_{\theta}<27.3\right)$, at depths of about $800 \mathrm{~m}$ in the Sargasso Sea and rising some $600 \mathrm{~m}$ under the Gulf Stream to occupy the top few hundred meters in the Slope Sea (Csanady and Hamilton, 1988).

Rintoul and Wunsch (1991) suggested that the Gulf Stream provides a large source of nitrate to the northern North Atlantic, being capable of balancing the nitrate budget for the North Atlantic. Pelegrí and Csanady (1991) showed the existence of a stream of nutrients associated to the Gulf Stream, centered at depths slightly shallower than the nutrient bearing stratum. As the stream moves northwards these layers approach the sea surface, and it is natural to hypothesize that at higher latitudes they can provide an input of nutrients to the seasonal surface mixed-layer. This will clearly depend on the details of the circulation pattern in this region, specifically on the epipycnal penetration of the upper thermocline flow into the northern North Atlantic. In this paper we collect previous results and provide new evidence that this is the case. One of our conclusions is that an appropriate closure of the water and nutrient balances by the Gulf Stream 
system requires calculation of epipycnal, rather than constant depth, transports.

The proposed principal role of the Gulf Stream in the nutrient budget and productivity enhancement of the northern North Atlantic, is accompanied by smaller scale $(10-100 \mathrm{~km})$ effects in sustaining local production. Newton (1978) suggested a similar behaviour between Gulf Stream meanders and jet stream waves: divergence and upward movements between a trough and the subsequent crest, with the opposite situation between the crest and the next trough. These vertical movements have been recently confirmed by Bower (1989) and Bower and Rossby (1989). Nutrient-rich waters approaching the photic region near the crest of meanders, must have important biological consequences in terms of primary and secondary production. Subsequent works have examined these ideas and shown the existence of periodic enhanced productivity associated with the meanders (Arnone et al., 1990; Flierl and Davis, 1993; Hitchcock et al., 1993; Lohrenz et al., 1993; Ashjian, 1993; Ashjian et al., 1994).

Another physical mechanism that may be responsible for localized supply of nutrients to the surface layers is diapycnal mixing. Pelegrí and Csanady (1991) have shown evidence of mixing between upper thermocline and surface layers, while Pelegrí and Csanady (1994) have argued that diapycnal mixing may be associated to frontogenetical, dynamically unstable, regions associated to the passage of meanders. Further support to the existence of diapycnal mixing in western boundary currents comes from the analysis of tritium distributions by Jenkins (1980) and Sarmiento et al. (1982). They observed large upper thermocline tritium concentrations in the northwest portion of the subtropical gyre, which can only be due to enhanced mixing between the surface and upper thermocline layers.

In this paper we will examine two mechanisms capable of draining nutrients transported by the Gulf Stream towards the photic layers. First (Section 2), we will consider the epipycnal irrigation of nutrients into the subpolar North Atlantic (basin-wide process). We will show how a nutrient stream flows centered on the 26.5-27.3 $\sigma_{\theta}$-band on its way to the northern North Atlantic, and how the nutrient transport in its upper layers gets depleted as they outcrop. And second (Section 3), we will consider the much smaller spatial ( $10-100 \mathrm{~km}$ ) intermittent (day-toweek) diapycnal transfer of nutrients within the Gulf Stream. We will show that diapycnal mixing takes place at the location of a nutrient stream, suggesting that its overall result is two-way exchange between nutrient-rich upper-thermocline and nutrient-poor surface layers of the Gulf Stream, with an upward net transfer of nutrients towards the photic zone. In this study we have used previous calculations (ours and of other authors) done in both $\sigma_{t}$ and $\sigma_{0}$ coordinates. This poses no difficulty because depth differences between $\sigma_{t}$ and $\sigma_{\theta}$ isolines are small in the upper $1000 \mathrm{~m}$, never exceeding $10 \mathrm{~m}$. Hence, the corresponding differences in nutrient transport would also be small, tending to zero when the nutrient stream approaches the surface mixed layer.

\section{The Nutrient Gulf Stream}

\subsection{Gulf Stream epipycnal nutrient transport}

Brewer and Dyrssen (1987) obtained gross estimates for the nitrate and phosphate transports through the Florida Straits and suggested that the Gulf Stream is a principal source of nutrients for the North Atlantic. Rintoul and Wunsch (1991) have shown the existence of net poleward transport of some $119 \mathrm{kmol} \mathrm{s}{ }^{1}$ of nitrate through $36^{\circ} \mathrm{N}$. They have indicated that most of this export is due to advection by the Gulf Stream in the $26.4<\sigma_{\theta}<27.3$ band. Pelegri and Csanady (1991), using the same data set, have shown that (alongstream) nutrient transport by the Gulf Stream approximately triples between the Florida Straits and $36^{\circ} \mathrm{N}$ (referenced to $2000 \mathrm{~m}$ ), 
(a)

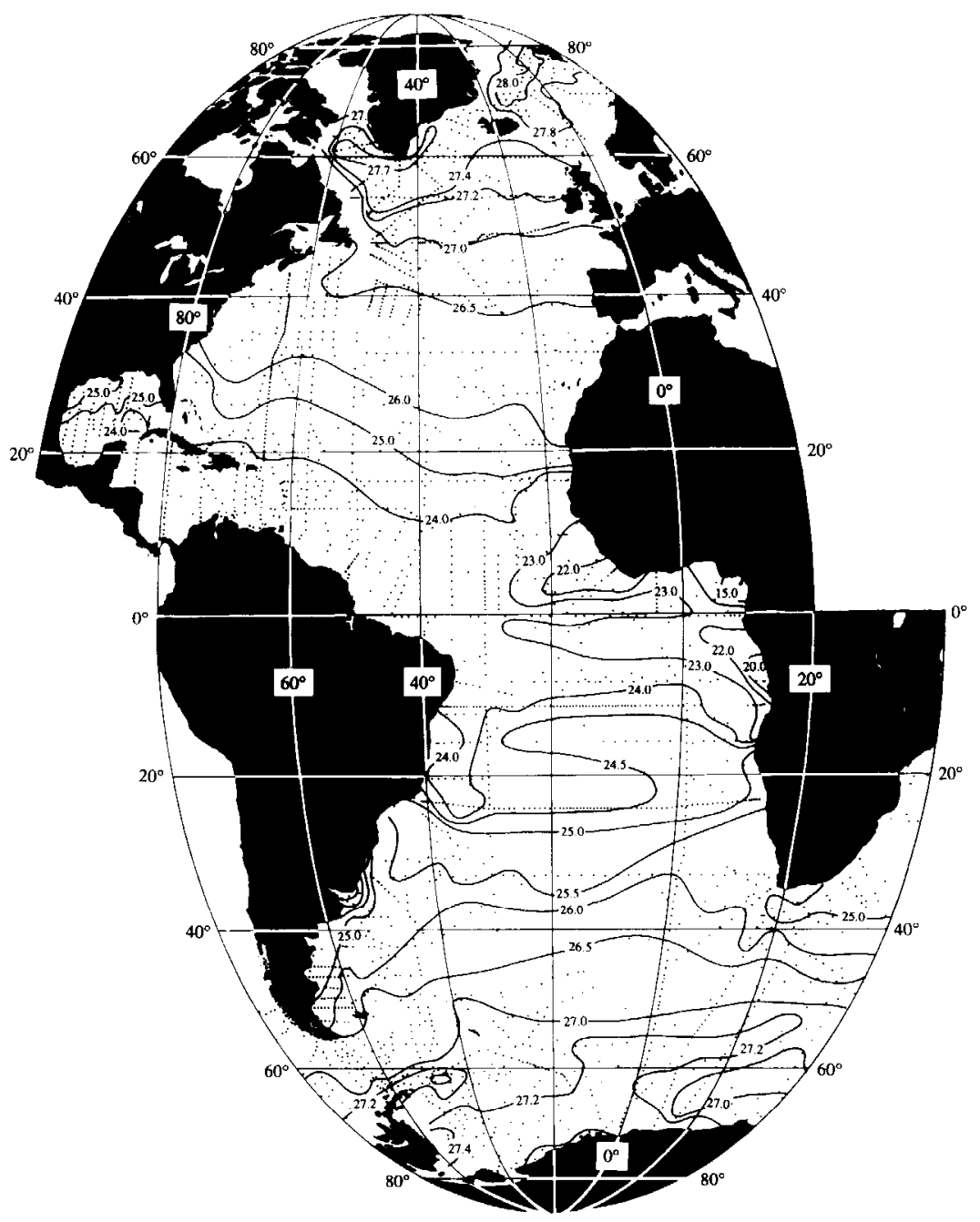

Fig. 1. Distribution of several properties in the Atlantic Ocean, reproduced from Reid (1994). (a) Outcropping of selected isopycnals. (b) Depth contours (units of $100 \mathrm{~m}$ ) for the $\sigma_{0}=26.75$ isopycnal.

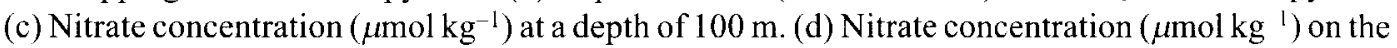
$\sigma_{\theta}=26.75$ isopycnal.

because of large (cross-stream) epipycnal inflow along the nutrient bearing stratum. They found that the Gulf Stream advects $863 \mathrm{kmol} \mathrm{s}^{-1}$ of nitrate beyond $36^{\circ} \mathrm{N}$, of which $486 \mathrm{kmol} \mathrm{s}^{1}(56 \%)$ are in the $26.5<\sigma_{t}<27.3$ band. Pelegrí and Csanady (1991) also calculated the total transport further downstream and showed that some portion recirculates but a significant fraction goes into the northern North Atlantic: $376 \mathrm{kmol} \mathrm{s}^{-1}$ of nitrate at $35^{\circ} \mathrm{W}$.

Rintoul and Wunsch (1991) have suggested that the nitrate imbalance is compensated by epipycnal recirculation of organic material, which is oxidated and provides the source of regenerated nitrate. This is consistent with Martin et al. (1987) and Sarmiento et al. (1990) ideas for the subtropical gyres of the North Pacific and North Atlantic, respectively, which suggest that differences in oxygen utilization rates are due to lateral (epipycnal) advection and decomposition 
(b)

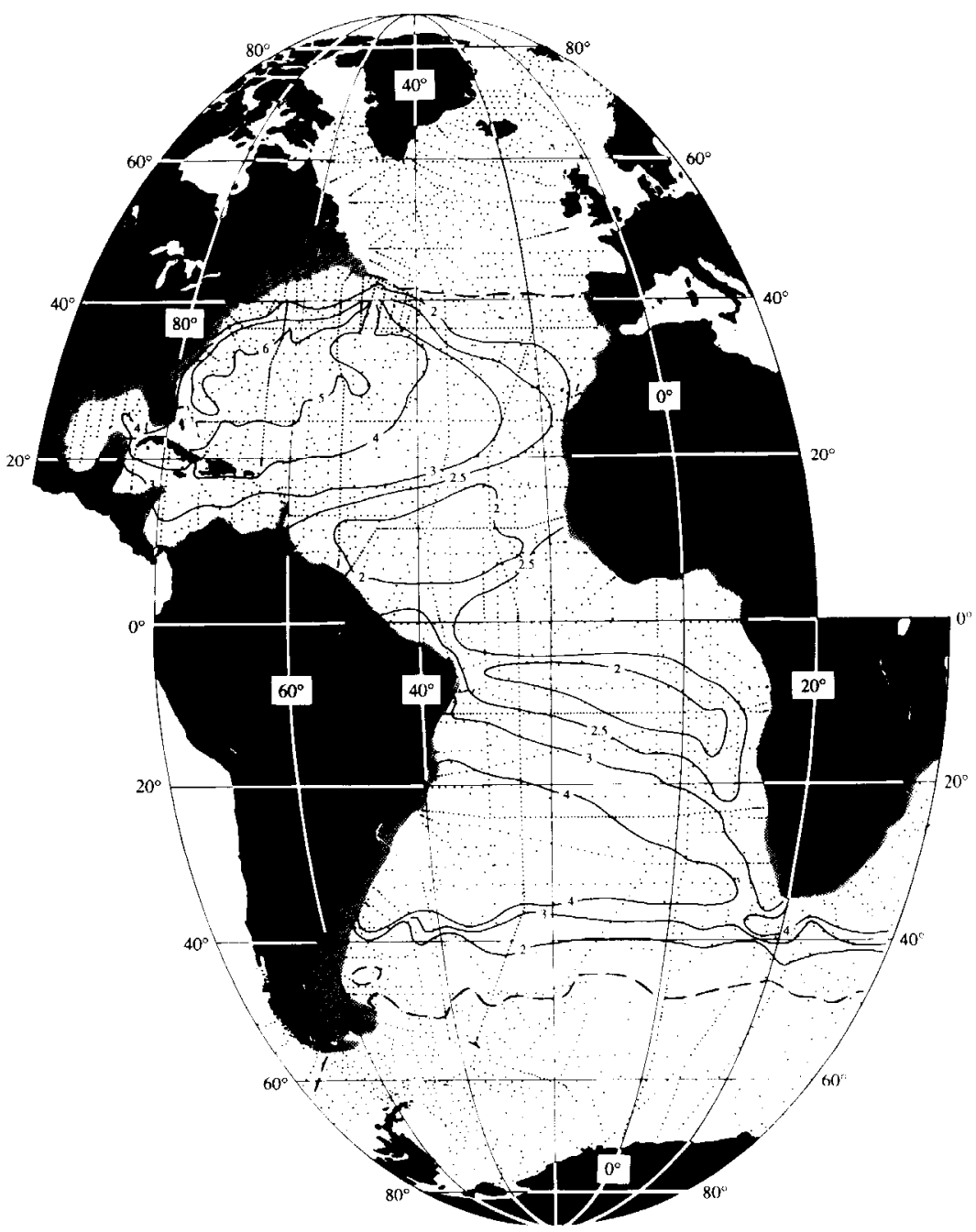

Fig. 1. (continued).

of slowly sinking particulate organic matter. In the North Atlantic the nitrogen would follow a cycle basically consisting on nitrate irrigation of its northern waters by the Gulf Stream system (Pelegrí and Csanady, 1991; Rintoul and Wunsch, 1991), high productivity and biomass production in this region (as observed in the CZCS satellite images of Esaias et al., 1986), and subduction/recirculation along the upper-thermocline layers of the subtropical gyre (with the nitrate imbalance being accounted for by dissolved or particulate organic nitrogen).

In Fig. 1 we have reproduced some recent maps for the Atlantic Ocean by Reid (1994), using data from all seasons. Figure 1(a) shows the outcropping of isopycnals, which are not substantially different to the wintertime outcropping maps of Levitus (1982). Figure 1(b) shows the depth contours of the $\sigma_{\theta}=26.75$ isopycnal, with the dashed line indicating its outcropping. The shoaling in the western North Atlantic corresponds to the location of the Gulf Stream system, and suggests that its entrance into the northern North Atlantic takes place at about $45^{\circ} \mathrm{W}$. Figures 1 (c) and 1 (d) 
(c)

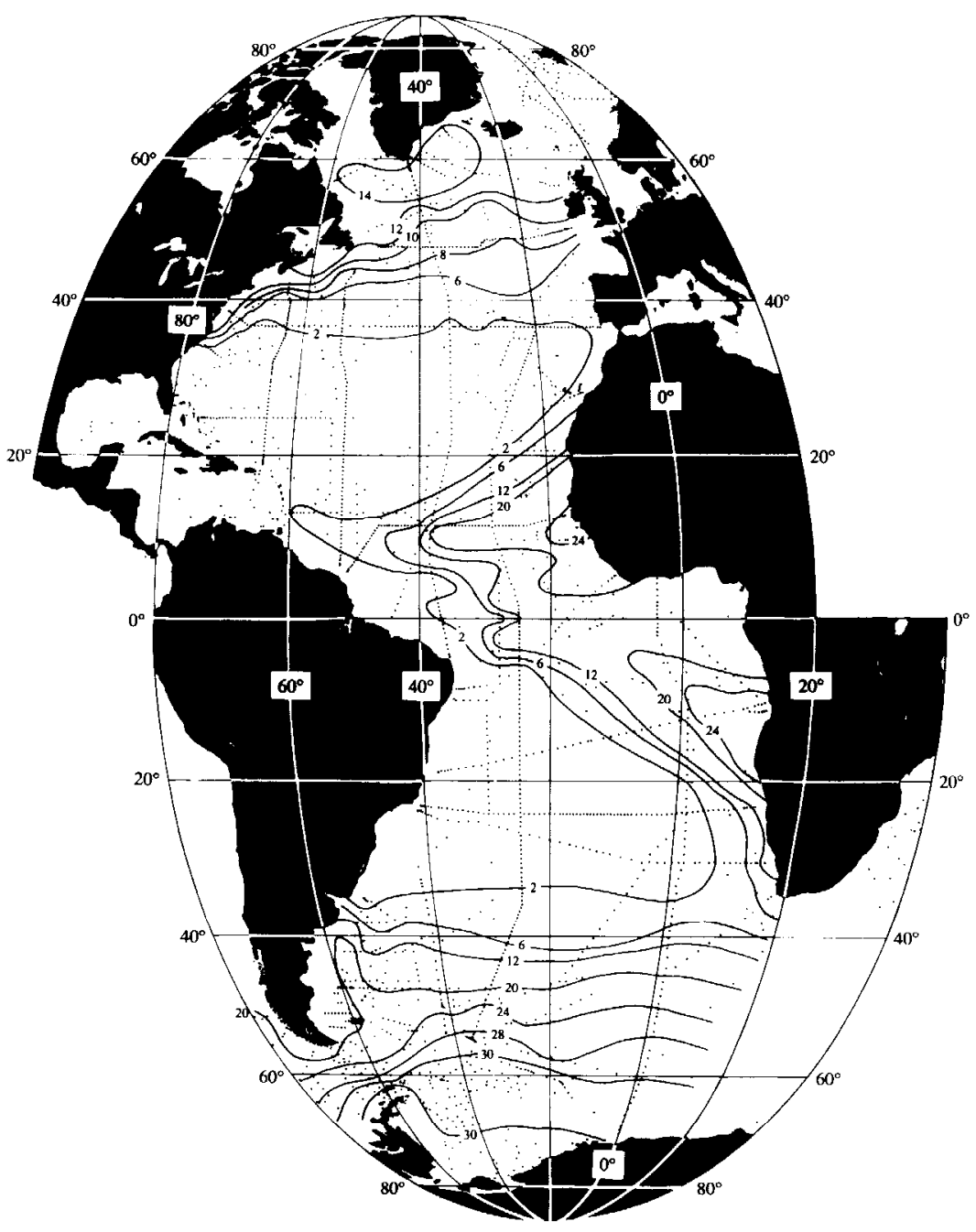

Fig. 1. (continued)

show the nitrate concentration at a depth of $100 \mathrm{~m}$ and on the $\sigma_{\theta}=26.75$ isopycnal, respectively. Figure 1(d) also shows the near surface concentration poleward from its outcropping position, where most hydrographic data was taken during the summer season (J. L. Reid, personal communication, 1994).

There are some important differences in the nitrate distributions at $100 \mathrm{~m}$ and on the $\sigma_{\theta}=$ 26.75 isopycnal over the North Atlantic. The distribution at $100 \mathrm{~m}$ shows rather homogeneously small values over the whole subtropical gyre, while the isopycnal distribution presents strong northeast-southwest gradients. The poleward nutrient transport is clear on this isopycnal through the large values in the northwestern margin of the gyre. Poleward of its outcropping position, the near surface (summer) nutrient concentrations are representative of the seasonal surface mixed layer, hence Fig. 1(d) suggests that the core of the nutrient stream flows deep into the northern North Atlantic along the surface mixed layer. 
(d)

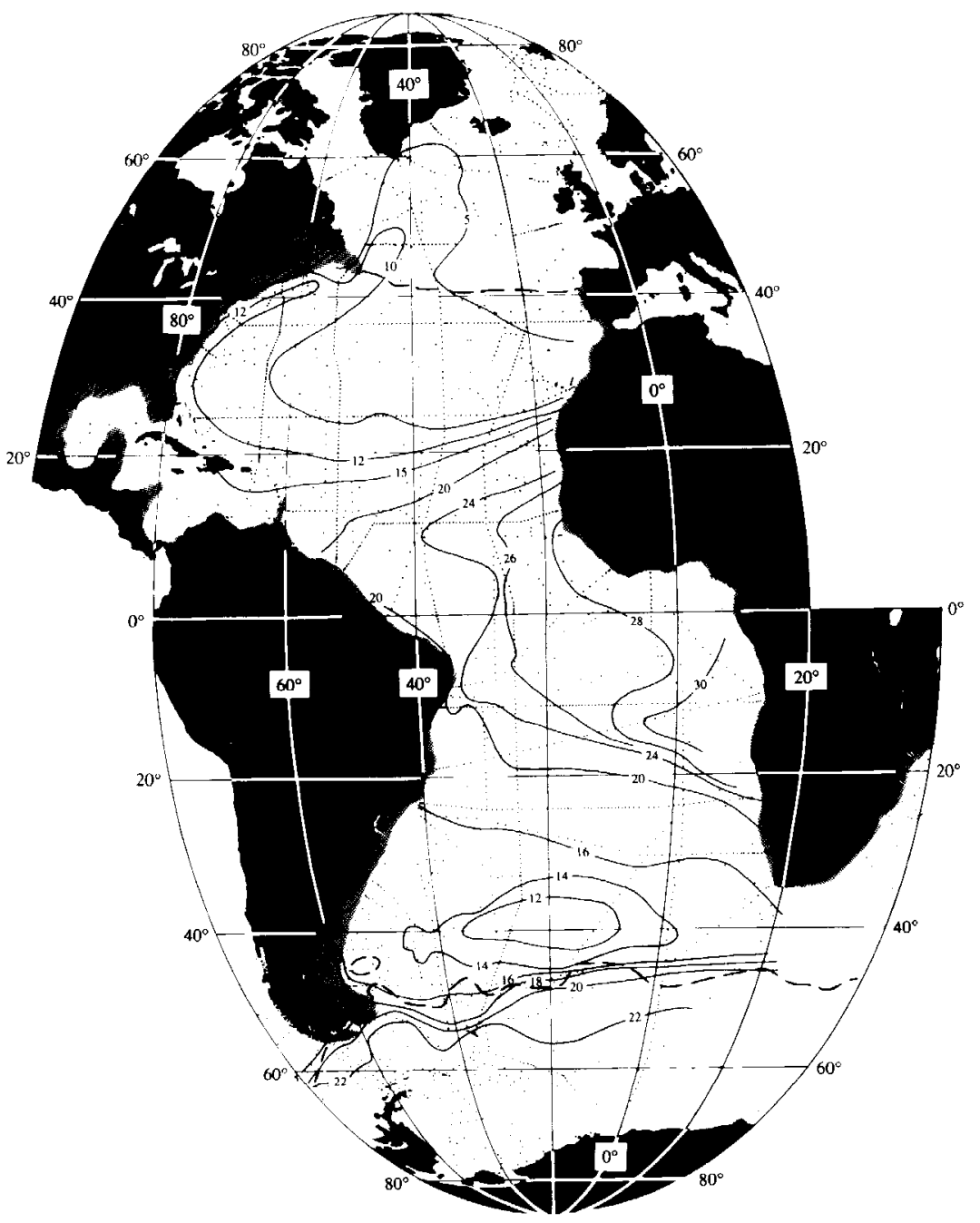

Fig. 1. (continued).

\subsection{Estimates of nutrient irrigation}

In order to discuss the location of the nutrient stream of the North Atlantic, or "Nutrient Gulf Stream", we have used four summer hydrographic sections from Pelegri and Csanady (1991). These will be identified by the latitude or longitude at which they approximately crossed the current: $36^{\circ} \mathrm{N}$ (June 1981), $64^{\circ} \mathrm{W}$ (April 1985), $53^{\circ} \mathrm{W}$ (May 1983), and $35^{\circ} \mathrm{W}$ (August 1983); their approximate location is shown in Fig. 1 of Pelegrí and Csanady (1991). We have also analyzed a short hydrographic section north of Cape Hatteras, but about $100 \mathrm{~km}$ southwest of section $36^{\circ} \mathrm{N}$, taken between September 6 and $9,1985$.

In Fig. 2 we present the combined $\sigma_{t}$ and nitrate flux distributions for all four Pelegri and Csanady's (1991) hydrographic sections (the nitrate flux distributions were already shown in their Figs. 3 and 6; in this and the following figures the small crosses indicate the location of nutrient data). The (alongstream) nitrate flux, or nitrate transport per unit area, is simply 


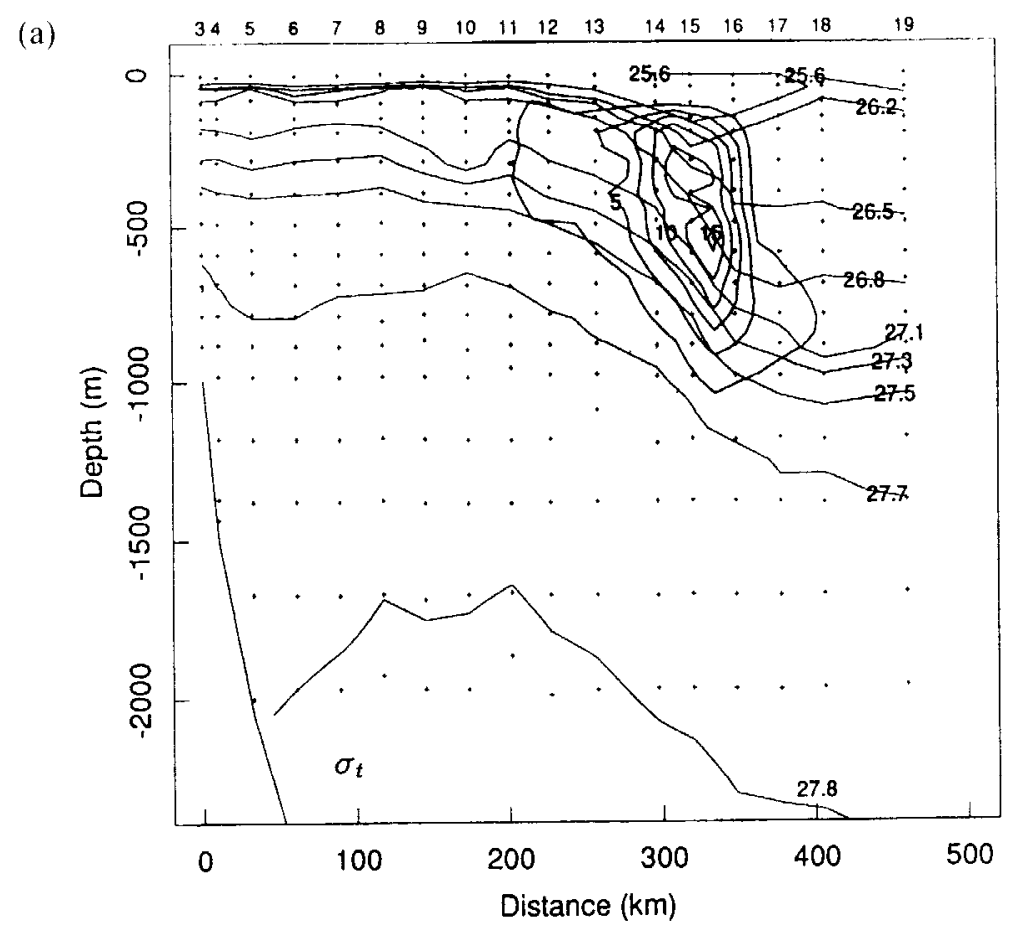

(b)

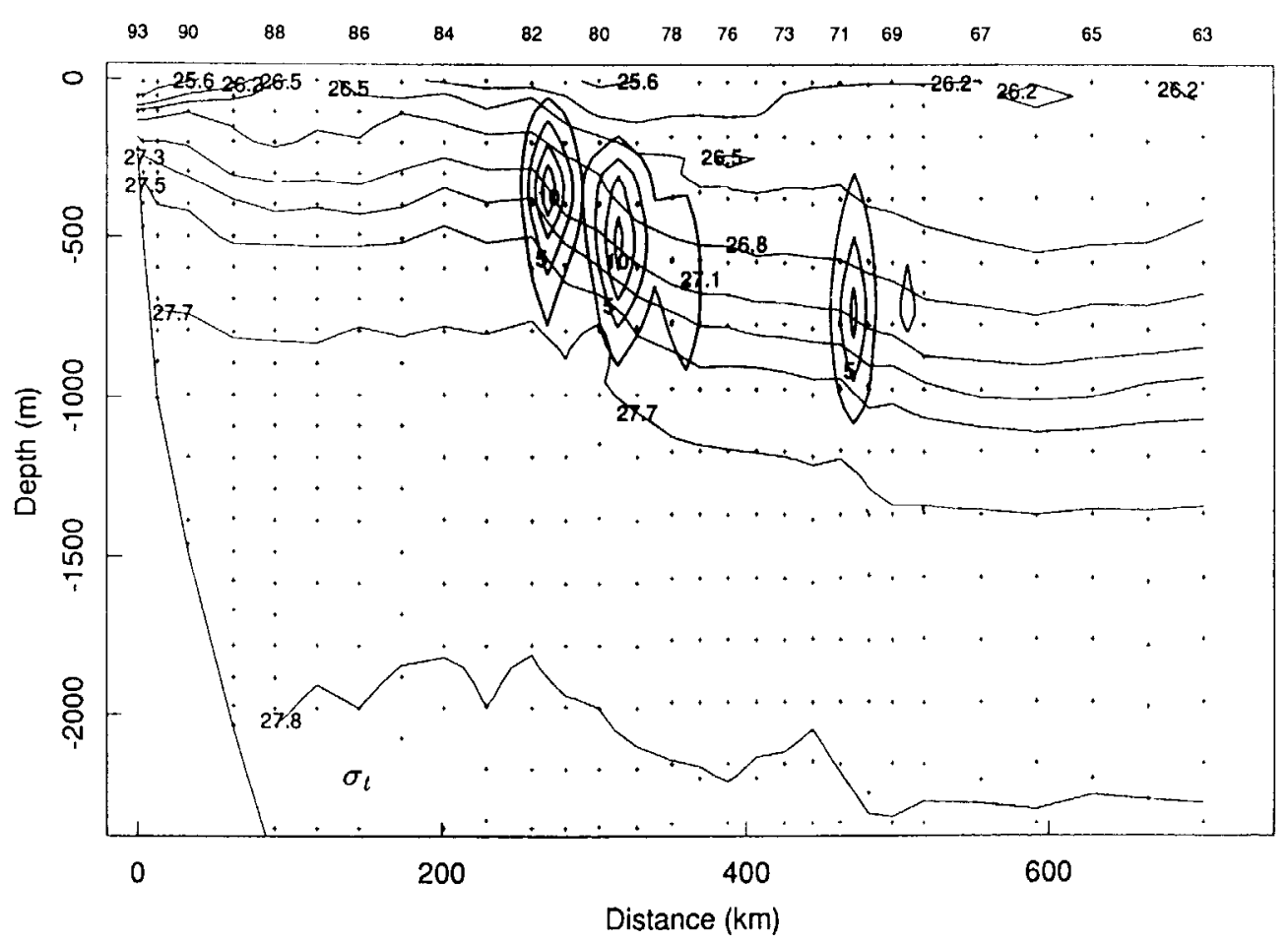

Fig. 2. Nitrate flux (mmol m $\mathrm{m}^{-2} \mathrm{~s}^{-1}$ ) and density $\left(\sigma_{t}\right)$ contours for sections (a) $36^{\circ} \mathrm{N}$, (b) $64^{\circ} \mathrm{W}$, (c) $53^{\circ} \mathrm{W}$, and (d) $35^{\circ} \mathrm{W}$. Please note the change in contour interval for Fig. 2(d). 
(c)

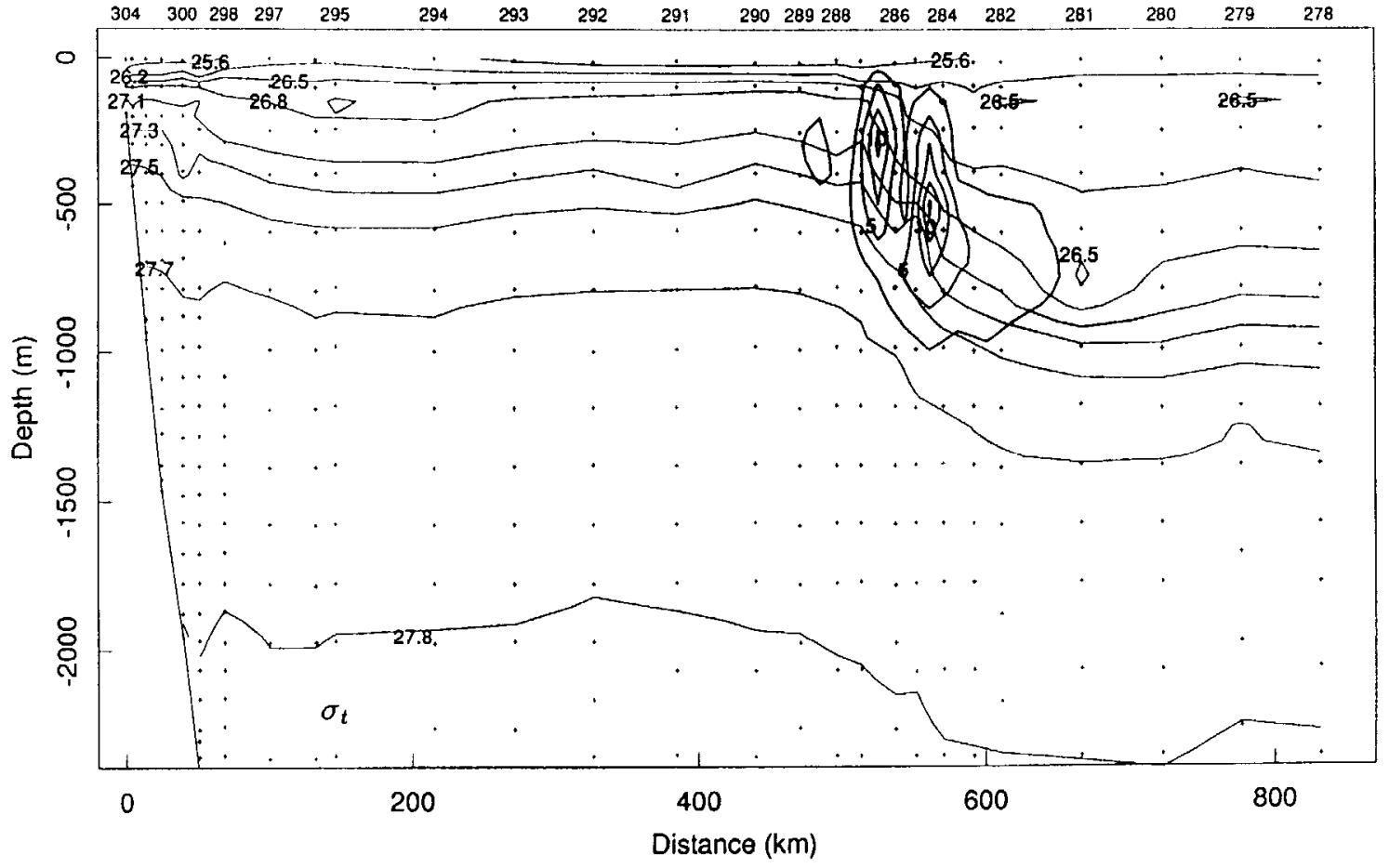

(d)

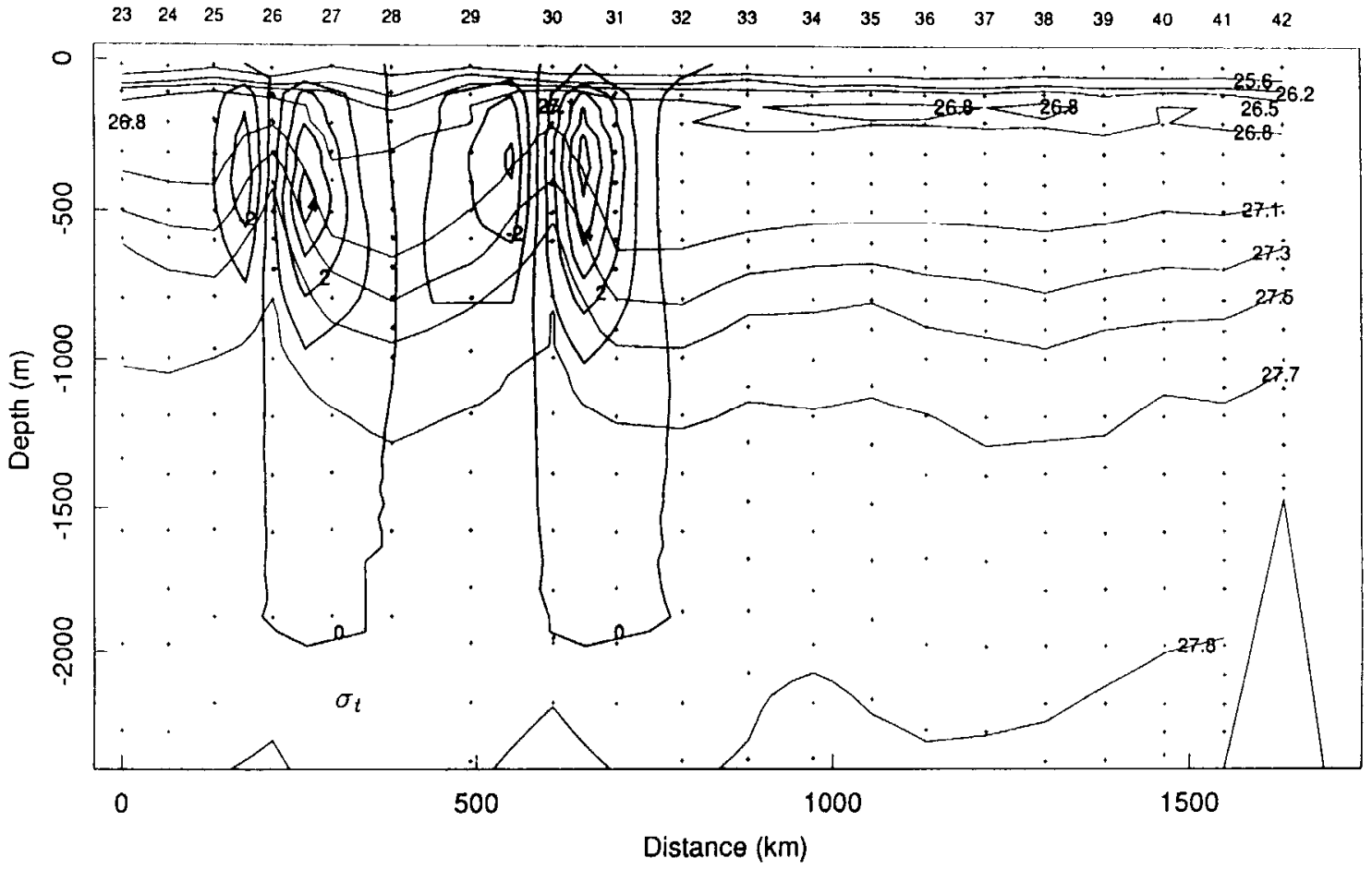

Fig. 2. (continued). 
(a)

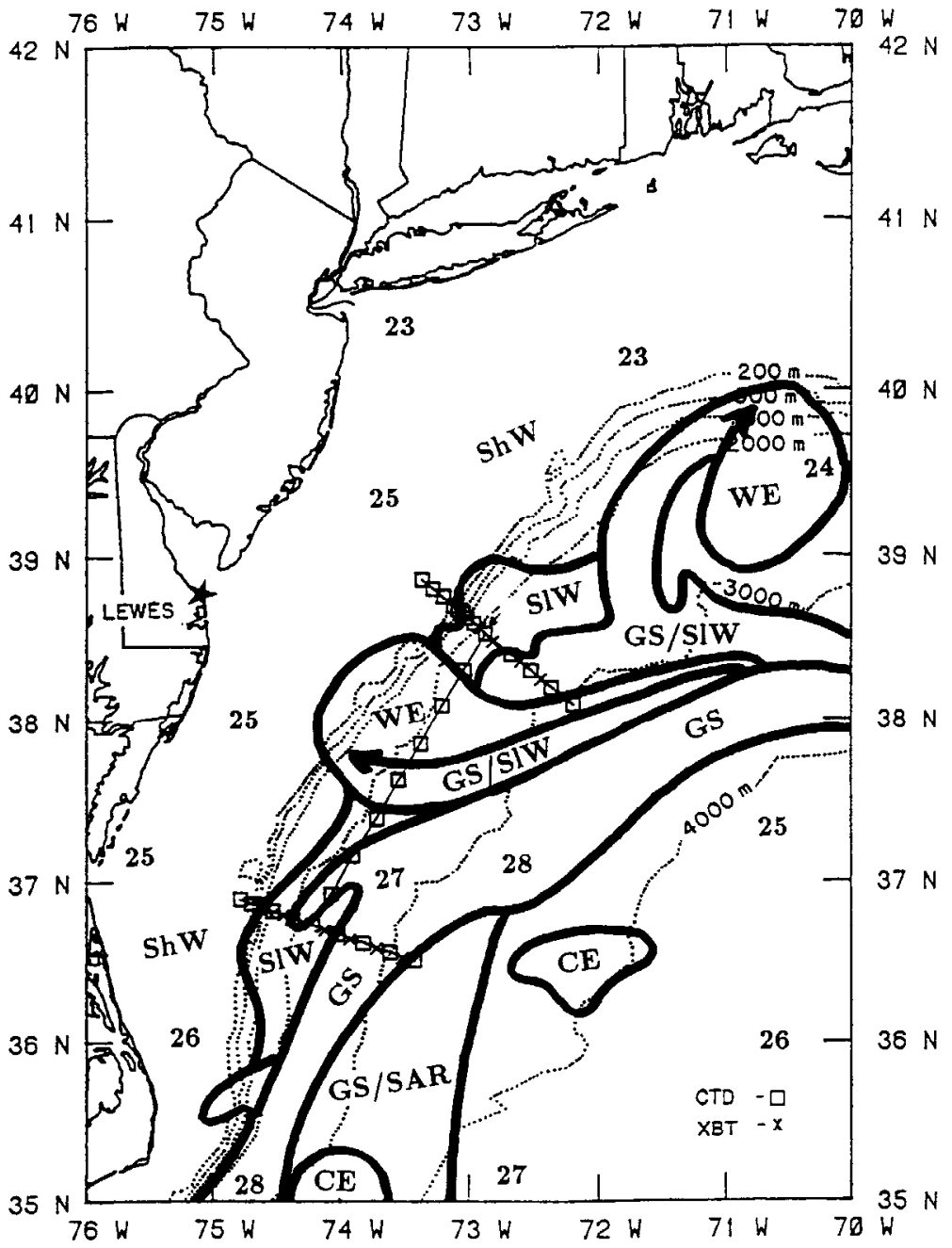

Fig. 3. (a) Oceanographic thermal analysis map for September 9, 1985, and location of hydrographic sections taken between September 6 and 9, 1985 (adapted from Brown et al., 1987). (b) Nitrate flux

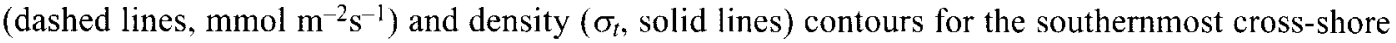
section in Fig. 3(a).

calculated as velocity times nitrate concentration. The velocity is obtained assuming geostrophy, with $2000 \mathrm{~m}$ as the zero velocity reference level, and the nitrate concentration is interpolated at the velocity positions using a smooth bivariate interpolant. These distributions illustrate that most of the nitrate flux is comprised in the 26.5-27.3 $\sigma_{t}$-band. In section $35^{\circ} \mathrm{W}$, however, the $\sigma_{t}=26.8$ surface has already outcroped (it coincides with the base of the seasonal mixed layer) and there is only very little nitrate flux above it. Notice that the North Atlantic Current appears to cross this hydrographic section several times: this is suggested by the similar amounts of water and nutrient transports in each crossing, consistent with a meandering of the same current rather than with its partition on different branches. Analogous behaviour in all sections can be found for phosphate and silicatc. 
(b)

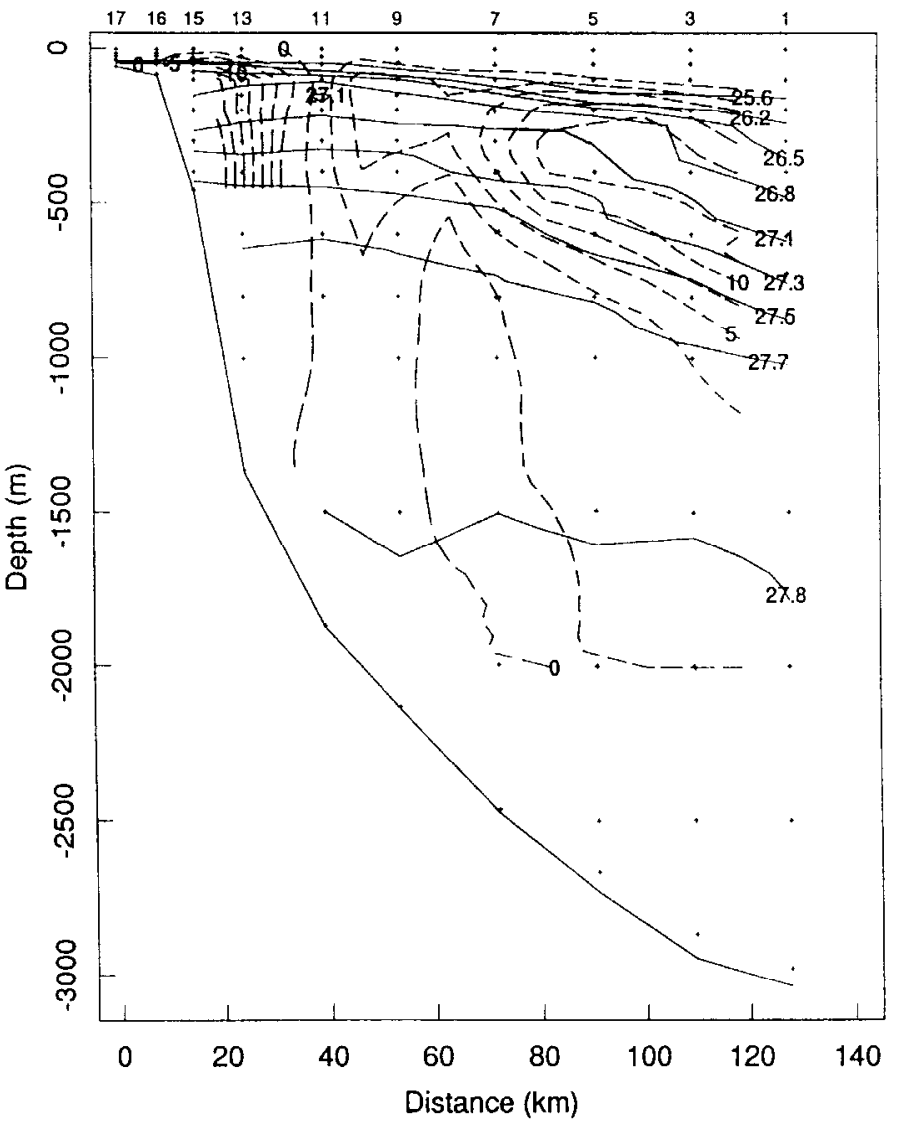

Fig. 3. (continued).

Figure 3(a) illustrates the location of the relatively short hydrographic section near Cape Hatteras together with the corresponding thermal analysis map, and shows that the Gulf Stream was located close to the coast (reproduced from Brown et al., 1987). This suggests that this section, despite its shortness, possibly comprises most of the Gulf Stream. Figure 3(b) shows the combined $\sigma_{t}$ and nitrate flux distributions (the velocity field is again calculated referred to 2000 $\mathrm{m}$, assuming zero bottom velocity for shallower regions). This last figure resembles Fig. 2(a) (section $36^{\circ} \mathrm{N}$ ) but because of its proximity to the coast it also shows the southward nitrate flux associated to the shelf and slopewater currents. The northward nitrate transport by the Nutrient Gulf Stream across this section is $530 \mathrm{kmol} \mathrm{s}$ ', smaller than (but of the same order of) the nitrate transport across section $36^{\circ} \mathrm{N}\left(863 \mathrm{kmol} \mathrm{s}^{1}\right)$, the difference being consistent with the fact that this section does not include the whole Gulf Stream. The southwestward coastal nitrate transport, however, is only a small fraction of this value: less than $20 \mathrm{kmol} \mathrm{s}{ }^{1}$.

Table 1 summarizes the water transport (Sv), and nitrate, phosphate and silicate transports $\left(\mathrm{kmol} \mathrm{s}^{-1}\right)$ across sections $36^{\circ} \mathrm{N}, 64^{\circ} \mathrm{W}, 53^{\circ} \mathrm{W}$, and $35^{\circ} \mathrm{W}$, for six selected isopycnal layers. (Notice that when the isopycnals get very close to each other it becomes difficult to estimate epipycnal water and nutrient transports from standard nutrient and hydrographic data. For this reason we have simply indicated when the water, nitrate, silicate and phosphate transports fall below $2 \mathrm{~Sv}$, and 10,5 and $1 \mathrm{kmol} \mathrm{s}^{-1}$, respectively.) The numbers in Table 1 show significant 
Table 1. Water (Sv) and nutrient $\left(\mathrm{kmol} \mathrm{s}^{-1}\right)$ transports along six isopycnal layers of the Nutrient Gulf Stream, across sections $36^{\circ} \mathrm{N}, 64^{\circ} \mathrm{W}, 53^{\circ} \mathrm{W}$, and $35^{\circ} \mathrm{W}$. For each layer and section we show four values, which correspond to water (top value), nitrate (second value), silicate (third value) and phosphate (bottom value) transports; values falling under $2 \mathrm{~Sv}$, and 10,5 and $1 \mathrm{kmol} \mathrm{s}{ }^{1}$, respectively, are indicated with a dash.

\begin{tabular}{cccccccccc}
\hline Layer & $36^{\circ} \mathrm{N}$ & $64^{\circ} \mathrm{W}$ & $53^{\circ} \mathrm{W}$ & $35^{\circ} \mathrm{W}$ & Layer & $36^{\circ} \mathrm{N}$ & $64^{\circ} \mathrm{W}$ & $53^{\circ} \mathrm{W}$ & $35^{\circ} \mathrm{W}$ \\
\hline $25.6-26.2$ & 6.6 & 5.5 & 8.7 & - & $26.8-27.1$ & 11.7 & 10.1 & 8.3 & 12.0 \\
& 44 & - & 15 & - & & 219 & 168 & 125 & 138 \\
& 21 & - & 6 & - & & 116 & 78 & 60 & 75 \\
& 2.6 & - & 1.5 & - & & 13.7 & 10.4 & 7.9 & 9.1 \\
$26.2-26.5$ & 8.0 & 21.1 & 16.5 & - & $27.1-27.3$ & 5.0 & 4.6 & 5.0 & 5.6 \\
& 59 & 59 & 49 & - & & 113 & 105 & 95 & 90 \\
& 28 & 21 & 23 & - & & 68 & 56 & 53 & 52 \\
& 3.2 & 3.4 & 2.1 & $-\cdots$ & & 7.2 & 6.6 & 6.3 & 4.1 \\
& & & & & & & & & \\
$26.5-26.8$ & 12.5 & 14.2 & 18.7 & - & $27.3-27.5$ & 3.6 & 3.9 & 4.3 & 3.5 \\
& 155 & 124 & 157 & - & & 87 & 89 & 94 & 64 \\
& 73 & 46 & 66 & - & & 56 & 51 & 59 & 38 \\
& 9.1 & 7.4 & 9.0 & - & & 5.7 & 5.7 & 6.3 & 4.1 \\
\hline
\end{tabular}

inputs near the surface between $64^{\circ} \mathrm{W}$ and $53^{\circ} \mathrm{W}$, and deeper between $53^{\circ} \mathrm{W}$ and $35^{\circ} \mathrm{W}$, which may be associated either with southward flowing coastal Labrador water or with recirculation within the western extreme of the subpolar gyre (Talley and McCartney, 1982; Csanady and Hamilton, 1988; see also Fig. 3(b)). The most striking feature, however, is that all nutrient transport above the $\sigma_{t}=26.8$ layer practically disappears beyond section $53^{\circ} \mathrm{W}$, due to the outcropping of this layer. Some of it may recirculate into the subtropical gyre but it is likely that most of it goes into the surface mixed layer of the northern North Atlantic (recall that our hydrographic sections were taken during summer, when a surface mixed layer covers very extense regions). Hence, the amount of nitrate going into the surface layer is of order $200 \mathrm{kmol}$ $\mathrm{s}^{-1}$, which clearly could account for the $119 \mathrm{kmol} \mathrm{s}^{-1}$ of poleward net export found by Rintoul and Wunsch (1991).

One is easily tempted to make rough estimates for the importance of this input to the northern North Atlantic. Over a volume with area of about $5 \times 10^{6} \mathrm{~km}^{2}$ and depth of $100 \mathrm{~m}$, such a nitrate source acting during four months (December through March) would account for an average input of $4 \mu \mathrm{mol} \mathrm{l}^{-1}$. This is of the right order of magnitude for the differences in concentrations between winter and post bloom values (e.g. Garside and Garside, 1993; Marra and Ho, 1993). Furthermore, we can expect that this input will still take place during the spring bloom, helping to maintain it for longer periods (this is because the North Atlantic Current velocities at these levels are of order $0.2-0.4 \mathrm{~m} \mathrm{~s}^{-1}$, faster than the northward advance of the pycnocline during stratification). We do not intend to pursue this problem here, but only to point out at its importance. For example, this input should be taken into account when modelling the bloom in order to not underestimate new production.

In Fig. 4 we present the nitrate flux across section $36^{\circ} \mathrm{N}$ in isopycnic coordinates. In this case the CTD data (available as averaged values over $2 \mathrm{~m}$ depth intervals) were smoothed using a 


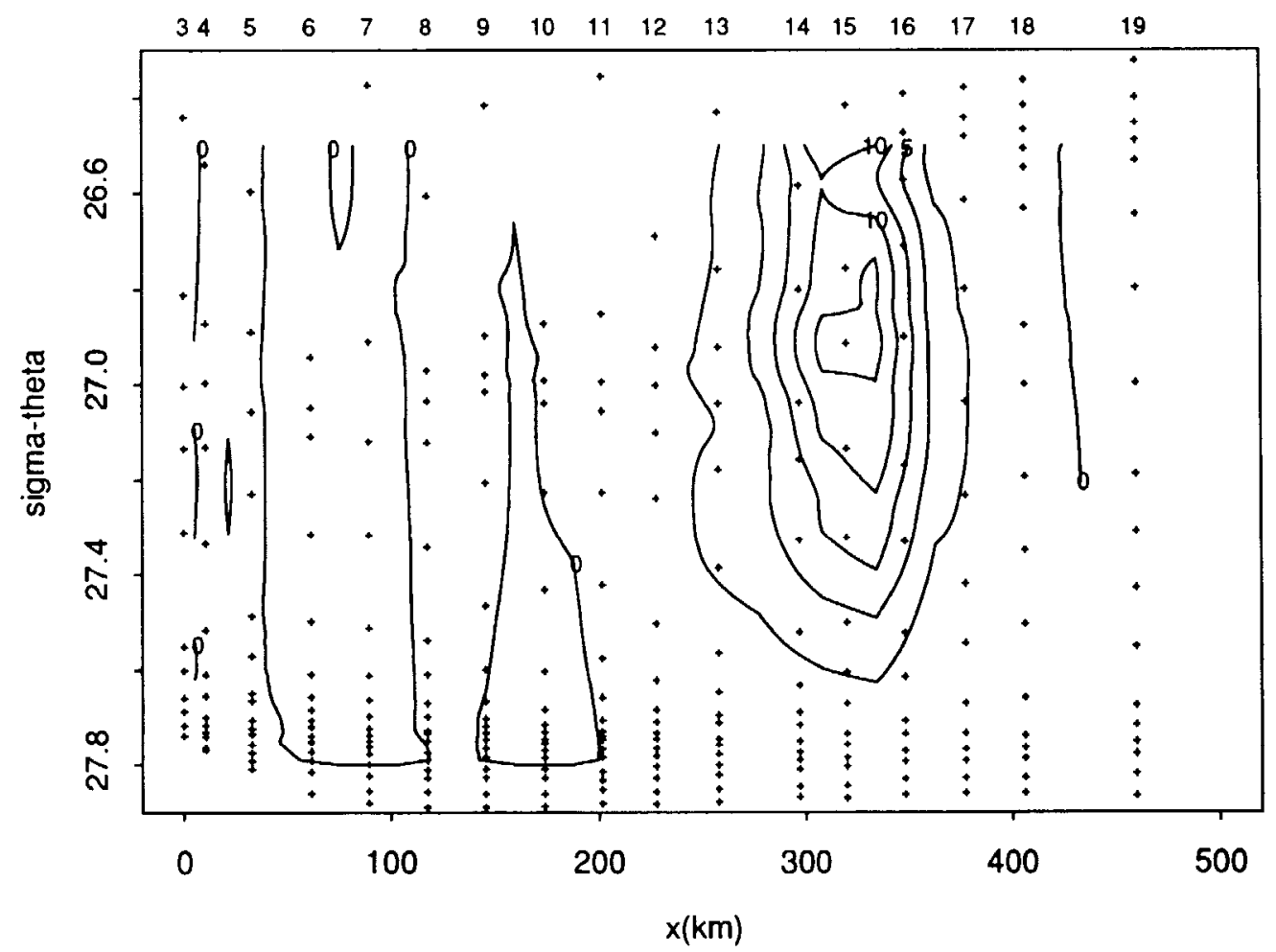

Fig. 4. Nitrate flux $\left(\mathrm{mmol} \mathrm{m}^{-2} \mathrm{~s}{ }^{1}\right)$ in isopycnic coordinates for section $36^{\circ} \mathrm{N}$, defining the location of the lower portion of the Nutrient Gulf Stream.

running filter to $16 \mathrm{~m}$ averages, and subsequently interpolated to $\sigma_{\theta}$-surfaces separated by 0.01 intervals using cubic splines. Notice that the interpolation has not been extended above the $\sigma_{0}=$ 26.5 isopycnal because of the large stratification there, which yields too few data points to make this procedure accurate. The velocity field was then obtained in isopycnic coordinates, with the $\sigma_{\theta}=27.8$ as the reference isopycnal surface (see Pelegrí and Csanady, 1994, for the details). The much more sparse nitrate data was finally interpolated to the locations of the velocity field, using a smooth bivariate interpolant, in order to obtain the nitrate flux field. This figure emphasizes the bounded character of the Nutrient Gulf Stream: values greater than $10 \mathrm{mmol} \mathrm{m}{ }^{2} \mathrm{~s}^{1}$ occur in the $26.6<\sigma_{\theta}<27.2$ range, with maximum values close to $15 \mathrm{mmol} \mathrm{m}^{2} \mathrm{~s}^{1}$ near the $\sigma_{\theta}=26.8$ isopycnal. Another smaller maximum, located in the $26.2<\sigma_{\theta}<26.55$ range (see Fig. 2(a)), only exhibits its deepest portion in this figure.

The penetration of the surface North Atlantic Current into the subpolar gyre is clear from geostrophic calculations (Levitus, 1982; Reid, 1994), drifting buoy trajectories (Richardson, 1983), and model results (e.g. Smith et al., 1990). The prominent tongue of nitrate that irrigates the surface waters of the northwestern North Atlantic (Fig. 1(d)) is further evidence of its origin from Gulf Stream waters. Our results suggest that its origin is not the surface Gulf Stream waters, but the Nutrient Gulf Stream flowing along the upper thermocline isopycnal layers of the western boundary current. This epipycnal irrigation of the northern North Atlantic surface waters is indeed consistent with the presence of positive Ekman pumping velocities in this region (Leetma and Bunker, 1978). 


\section{Shear-Induced Mixing and Enhanced Productivity in Gulf Stream Meanders}

\section{I Former evidence of diapycnal mixing}

As discussed in the Introduction, there are several processes associated to Gulf Stream meanders that may enhance local productivity. We turn now into one of such processes, its peculiarity being that it brings nutrient-rich waters towards the surface layers through diapycnal transfer rather than by epipycnal movements. This is intermittent shear-induced mixing, taking place in some layers of the Gulf Stream, probably intensified during some frontogenetic phase of meanders. Its spatial and temporal scales are very different from those of the epipycnal irrigation of the northern North Atlantic, day-to-week versus seasonal and 10-100 km versus basin-wide.

Hitchcock et al. (1993) have indicated that the main physical mechanisms controlling the pigment distribution are (1) the outcropping of the nutrient bearing strata during spring, (2) meander-induced nutrient upwelling, and (3) Gulf Stream-ring interactions. The importance of these upwelling/downwelling movements appears in concordance with the productivity model by Flierl and Davis (1993). The work by Lohrenz et al. (1993), however, suggests a potentially important role of mixing-induced nutrient injection, taking place downstream of a meander crest. Ashjian et al. (1994) also report elevated zooplankton biomass in such a region, although they ascribe it to flow convergence and entrainment of slopewater. Hitchcock et al. (1993) isopycnal maps of pigment concentrations also show several maxima taking place beyond a meander's crest, although they think that it is unlikely that these maxima are maintained by diapycnal mixing processes. Ishizaka et al. (1992) used ocean color and thermal infrared images, as well as in situ chlorophyll and temperature data, to study the phytoplankton distribution around the Izu Peninsula of Japan. They found high pigment concentrations at the crest of a Kuroshio meander, and suggested that it may be the result of either upwelling or mixing.

Pelegrí and Csanady $(1991,1994)$ have discussed the possibility of intermittent shearinduced diapycnal mixing in the upper-thermocline layers of the Gulf Stream, taking place during frontogenetical phases of meanders. Pelegri and Csanady (1991) found that the $\sigma_{\theta}=26.8$ isopycnal approximately separates positive nutrient anomalies in the surface layers from negative nutrient anomalies in the upper-thermocline layers. They used a two-box model to show that this is consistent with upward entrainment and two-way exchange between the upper-thermocline and surface layers. More recently, Pelegrí and Csanady (1994) have shown that anomalies in both potential vorticity and vertical distance between isopycnals are indicative of regions with dominant diapycnal convergence. They suggested that diapycnal mixing is triggered when the isopycnals approach each other while the diapycnal gradient of the along-stream velocity $(\partial v / \partial \rho)$ remains constant or increases, causing subcritical gradient Richardson numbers. This is likely to occur between the crest and following trough of Gulf Stream meanders, when frontogenesis probably develops in analogy to what happens in atmospheric jet stream waves.

Evidence for diapycnal mixing within the Gulf Stream, however, may come from early works by Richards and Redfield (1955) and Stefánsson and Atkinson (1971). Richards and Redfield (1955) studied the evolution of oxygen anomalies, as compared with Sargasso Sea waters, along the course of the Gulf Stream. They reported relatively large and patchy negative oxygen anomalies, mostly in the 26-26.5 $\sigma_{t}$-range but extending down to $\sigma_{t}=27$, which they related to the low oxygen content of water arriving through the Florida Straits. They explained the negative surface oxygen anomalies in the Gulf Stream by arguing that the surface stratum 

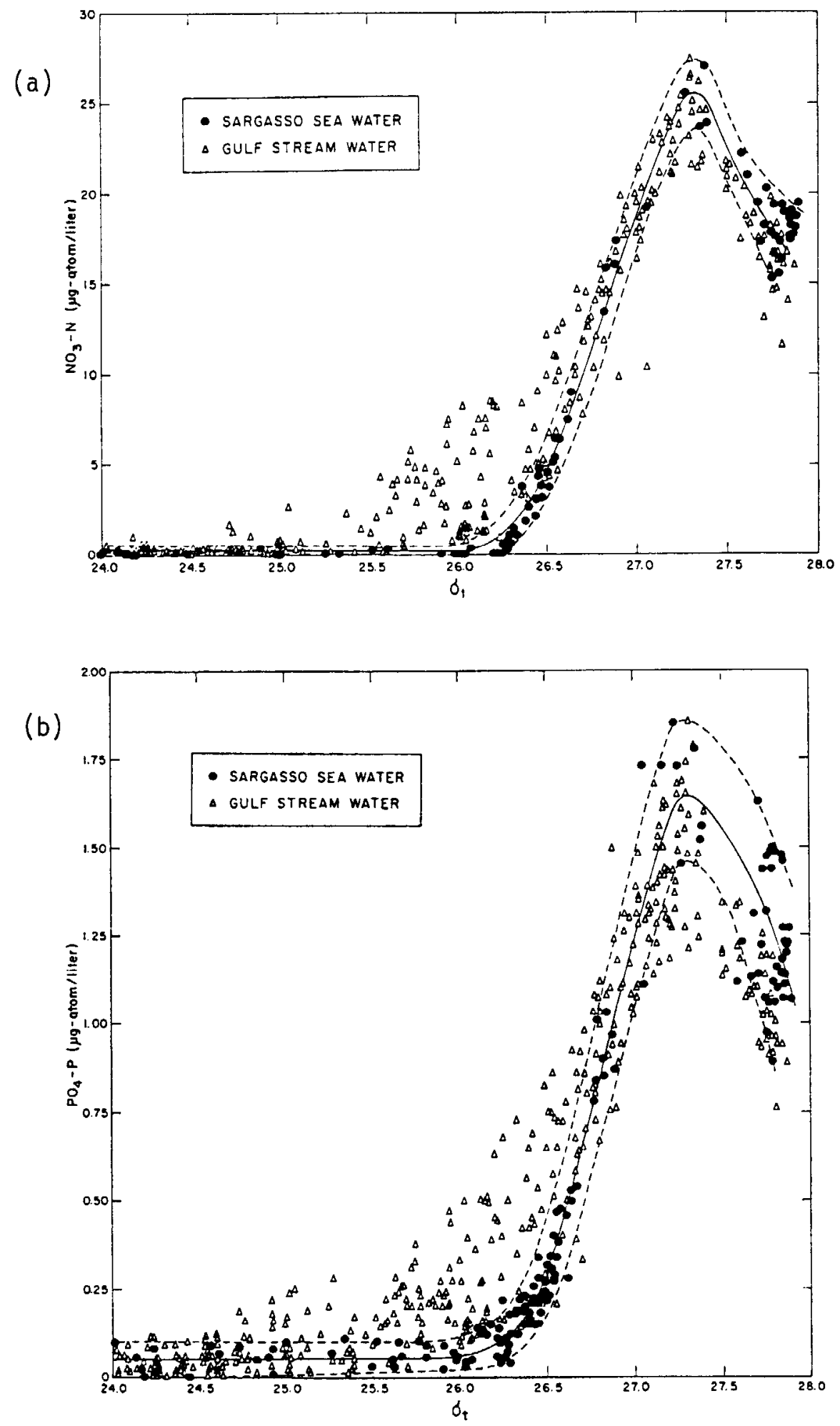

Fig. 5. (a) Nitrate and (b) phosphate concentrations $\left(\mu \mathrm{mol}^{1}\right)$ as a function of density $\left(\sigma_{t}\right)$. Circles and triangles represent observations taken in the Sargasso Sea and the Gulf Stream, respectively. Reproduced from Stefánsson and Atkinson (1971). 
$\left(26.0<\sigma_{t}<26.5\right)$ corresponds to the swiftest flowing waters, and speculated that the patchiness in the oxygen anomalies may be due to the Gulf Stream having several branches. This idea, if true, could provide an explanation for the positive surface nutrient anomalies, but not so for the negative upper-thermocline anomalies.

Stefánsson and Atkinson (1971) studied the distribution of nitrate and phosphate anomalies in several sections across the Gulf Stream, off the North Carolina coast, again as compared with Sargasso Sea waters. Figure 5, reproduced from their work, shows large positive anomalies in the 25.0-26.6 $\sigma_{t}$-band and smaller, but significant, negative anomalies in the $27.0-27.5 \sigma_{t}$-band. Stefánsson and Atkinson suggested that the positive anomalies are caused by waters of Caribbean origin, in accordance with Richards and Redfield (1955) earlier interpretation arising from opposite oxygen anomalies. However, this explanation cannot justify the negative nutrient anomalies, because of high nutrient concentrations in Caribbean thermocline waters. Densities in the Florida Straits do get at least as large as $\sigma_{t}=27.3$, and one would expect that these waters would carry positive nutrient anomalies in the thermocline. A complementary explanation for the patchy nutrient (and oxygen) anomalies, positive (negative) in the surface layers and negative (positive) in the upper thermocline, is intermittent two-way exchange. Positive nutrient anoma-

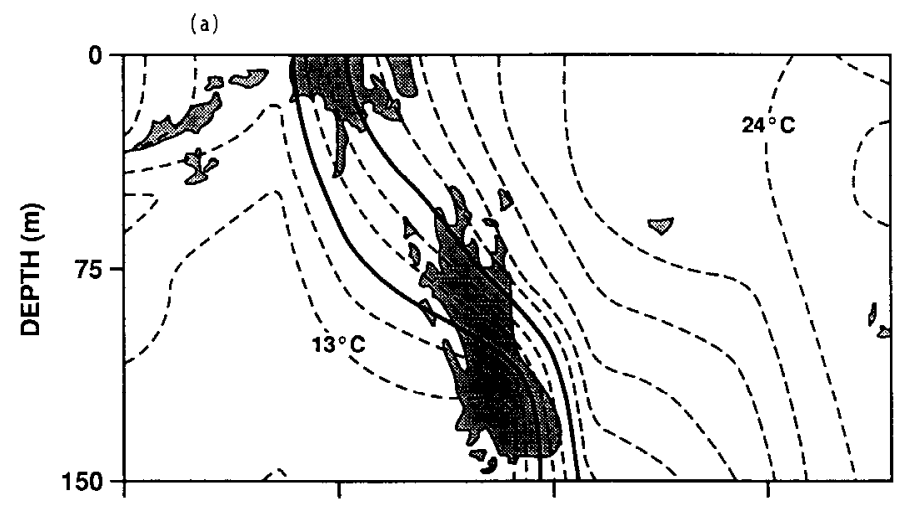

(b)

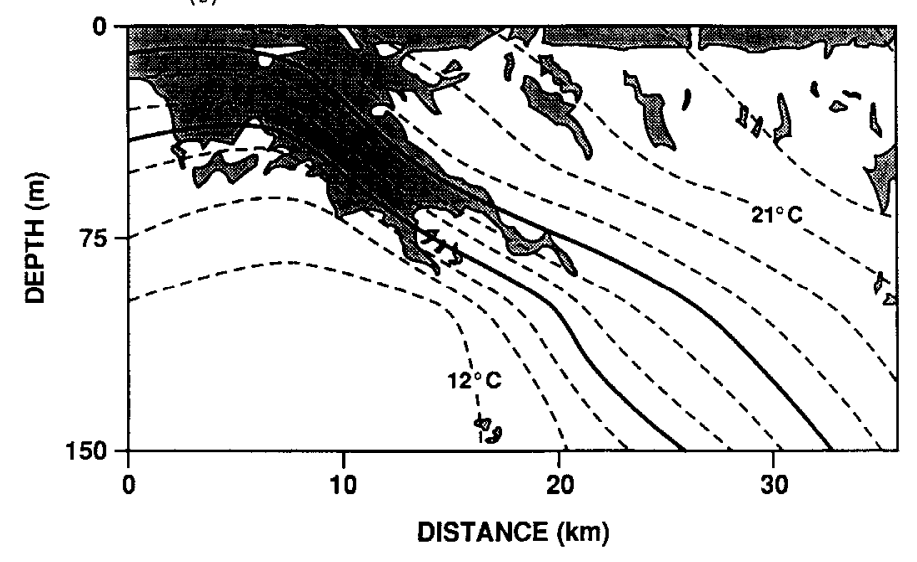

Fig. 6. Temperature distribution (dashed lines; solid lines correspond to $T=15$ and $18^{\circ} \mathrm{C}$ ) and regions with high phytoplankton concentration (shaded areas) for two nearby transects across the Gulf Stream (adapted from Arnone et al., 1990). The transect in (a) was taken slightly before a meander's trough while the transect in (b) was taken slightly before the subsequent crest. 
lies at the surface and negative anomalies below (and the opposite for oxygen) simply mean reduced gradients, consistent with the idea of diapycnal mixing.

The distribution of phytoplankton may also be used as an indicator of mixing processes in meanders. Figure 6, adapted from the work by Arnone et al. (1990), shows the temperature distribution (dashed lines; solid lines are for $T=15$ and $18^{\circ} \mathrm{C}$ ) and the regions of enhanced phytoplankton, zooplankton and small animal concentration (shaded regions), for two transects across the Gulf Stream. The top illustration corresponds to a transect taken slightly before the trough of a meander, the frontogenetical stage being illustrated by the presence of rather strong horizontal temperature gradients. The bottom figure comes from a transect taken slightly before the crest of the next meander. Arnone et al. (1990) pointed out that the downward and upward movements of phytoplankton (used as a tracer) show shrinking (convergence) and stretching (divergence) of the isopycnal layers, in agreement with Bower's (1989) calculations of convergence-divergence from the movement of isopycnal floats. The transects, however, also show the spread of phytoplankton across isothermal layers, which may be used as an indicative of diapycnal mixing. Reference to the isotherms $T=15$ and $18^{\circ} \mathrm{C}$ shows that the isothermal extension of phytoplankton is noticeably larger in the transect taken near the trough, suggesting that the frontogenetical stage may be followed by diapycnal mixing.

\subsection{Diapycnal mixing and the nutrient stream}

In Pelegri and Csanady (1994) we introduced the concept of density tendency $w_{\rho}$ as the material change of density on relatively long time scales (as compared with the time scale over which mixing takes place):

$$
w_{\rho} \equiv \frac{D \tilde{\rho}}{D t} \equiv \frac{\partial \tilde{\rho}}{\partial t}+\tilde{u} \frac{\partial \tilde{\rho}}{\partial x}+\tilde{v} \frac{\partial \tilde{\rho}}{\partial y}+\tilde{w} \frac{\partial \tilde{\rho}}{\partial z}=-\nabla \cdot \boldsymbol{F}
$$

where $F \equiv\left(\overline{u^{\prime} \rho^{\prime}}, \overline{v^{\prime} \rho^{\prime}}, \overline{w^{\prime} \rho^{\prime}}\right)$ is the density flux vector. Tilded quantities refer to average values over the long time scales, while primed quantities refer to short-time fluctuations which are responsible for the resulting mixing: $\rho=\tilde{\rho}+\rho^{\prime}, u=\tilde{u}+u^{\prime}$, etc. In isopycnic coordinates $w_{p}$ is the natural quantity to consider when studying diapycnal mixing, to be estimated from

$$
w_{\rho} \simeq-\frac{\partial F_{z}}{\partial z}=\frac{\partial}{\partial z}\left(\frac{K}{J}\right)
$$

where $J=\partial z / \partial \tilde{\rho}$, and $K$ is the eddy density diffusivity which is parameterized as an inverse function of the gradient Richardson number $R i$.

Our results in Pelegrí and Csanady (1994) showed several regions with relatively small $R i$ and $J$ values in the $26.5-27.1 \sigma_{\theta}$-band, which cause $w_{\rho}$ peaks of alternating sign. We hypothesized there that spatially and temporally recurrent positive and negative $w_{p}$ values, intensified during frontogenetical unstable phases in Gulf Stream meanders, would induce the two-way mean diapycnal mass transfer observed in Pelegri and Csanady (1991). In the previous section we have seen (Fig. 4) that this isopycnal band precisely corresponds to the core of the Nutrient Gulf Stream, where nutrients are constantly replenished by alongstream and cross-stream epipycnal flow. The natural consequence, to be discussed next, is that diapycnal mixing will also be responsible for mean upward nutrient transport. 
(a)

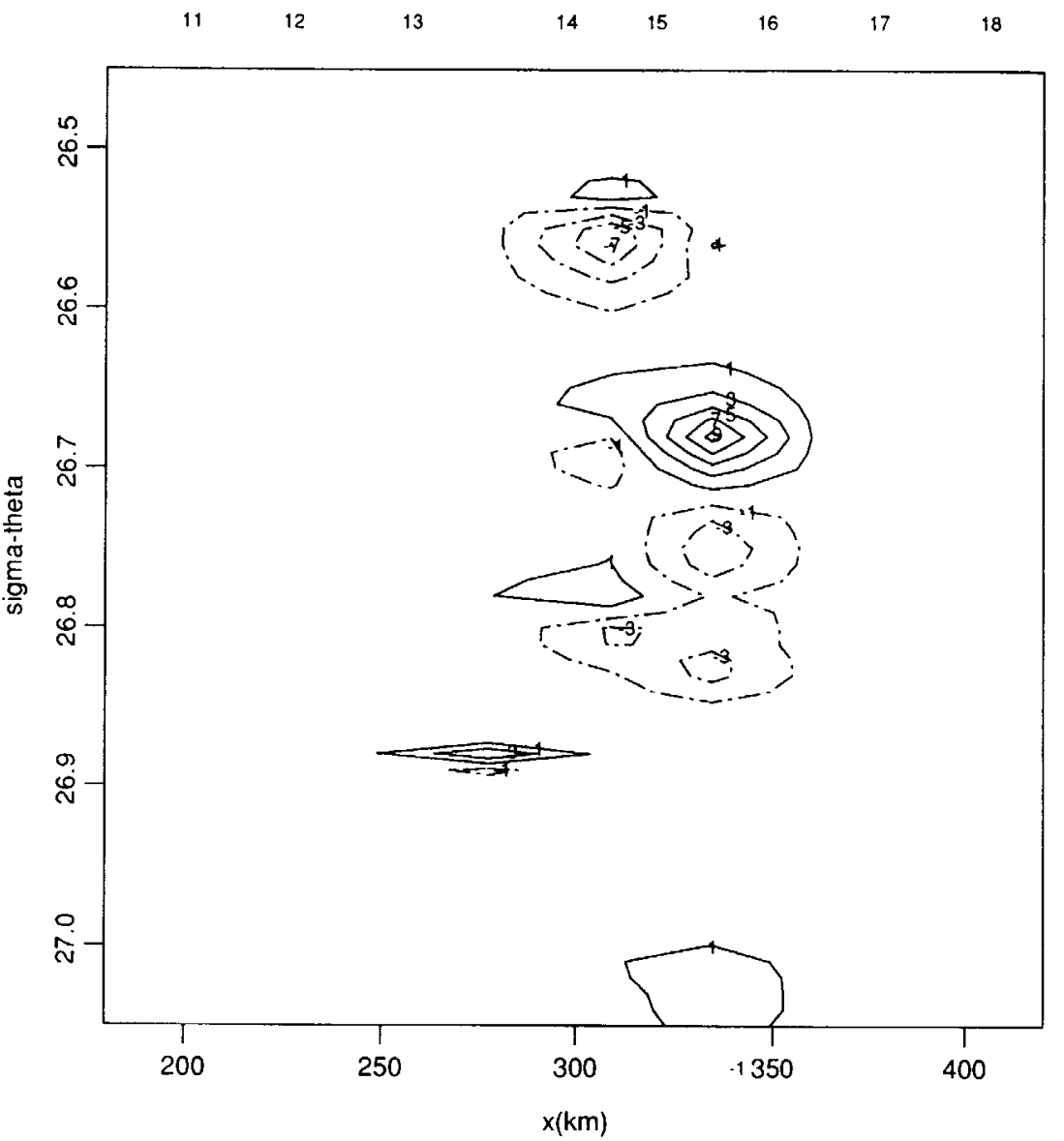

Fig. 7. (a) Density tendency, $w_{\rho}$, within the Nutrient Gulf Stream in section $36^{\circ} \mathrm{N}$, as a function of density $\left(\sigma_{\theta}\right)$ and offshore distance. Solid and dashed lines refer to positive and negative values, respectively, each unit corresponding to $2.6 \times 10^{-10} \sigma_{\theta} \mathrm{s}^{1}$ (adapted from Pelegrí and Csanady, 1994). (b) Nitrate concentration $\left(\mu \mathrm{mol} \mathrm{kg}{ }^{1}\right)$ in section $36^{\circ} \mathrm{N}$ as a function of density $\left(\sigma_{\theta}\right)$ and cross-stream distance. The shaded regions correspond to the above $w_{\rho}$ field.

Figure 7(a) shows the distribution of $w_{\rho}$ in a portion of section $36^{\circ} \mathrm{N}$, as a function of $\sigma_{\theta}$ and offshore distance (adapted from Pelegrí and Csanady, 1994). This figure shows that diapycnal mixing has several maxima within the upper thermocline layers of the Gulf Stream, in the core of the Nutrient Gulf Stream. The details of this figure depend on the smoothing done to the original data (necessary to eliminate all density inversions when using isopycnic coordinates), as well as on the chosen function for $K=K(R i)$. Its importance, however, lies on its alternating negative-positive character, which implies upward-downward transfer of water between adjacent isopycnal layers. It is convenient to recall that section $36^{\circ} \mathrm{N}$ was taken shortly after the crest of a meander, where frontogenesis takes place and produces the unstable conditions leading to diapycnal mixing.

Figure 7(b) shows the nitrate distribution for section $36^{\circ} \mathrm{N}$ as a function of $\sigma_{\theta}$ and offshore distance. The nitrate concentration is roughly constant along the isopycnals in the lower layers, up to about the $27.3 \sigma_{\theta}$-surface. Above these, the concentration isopleths depart from the hori- 
(b)

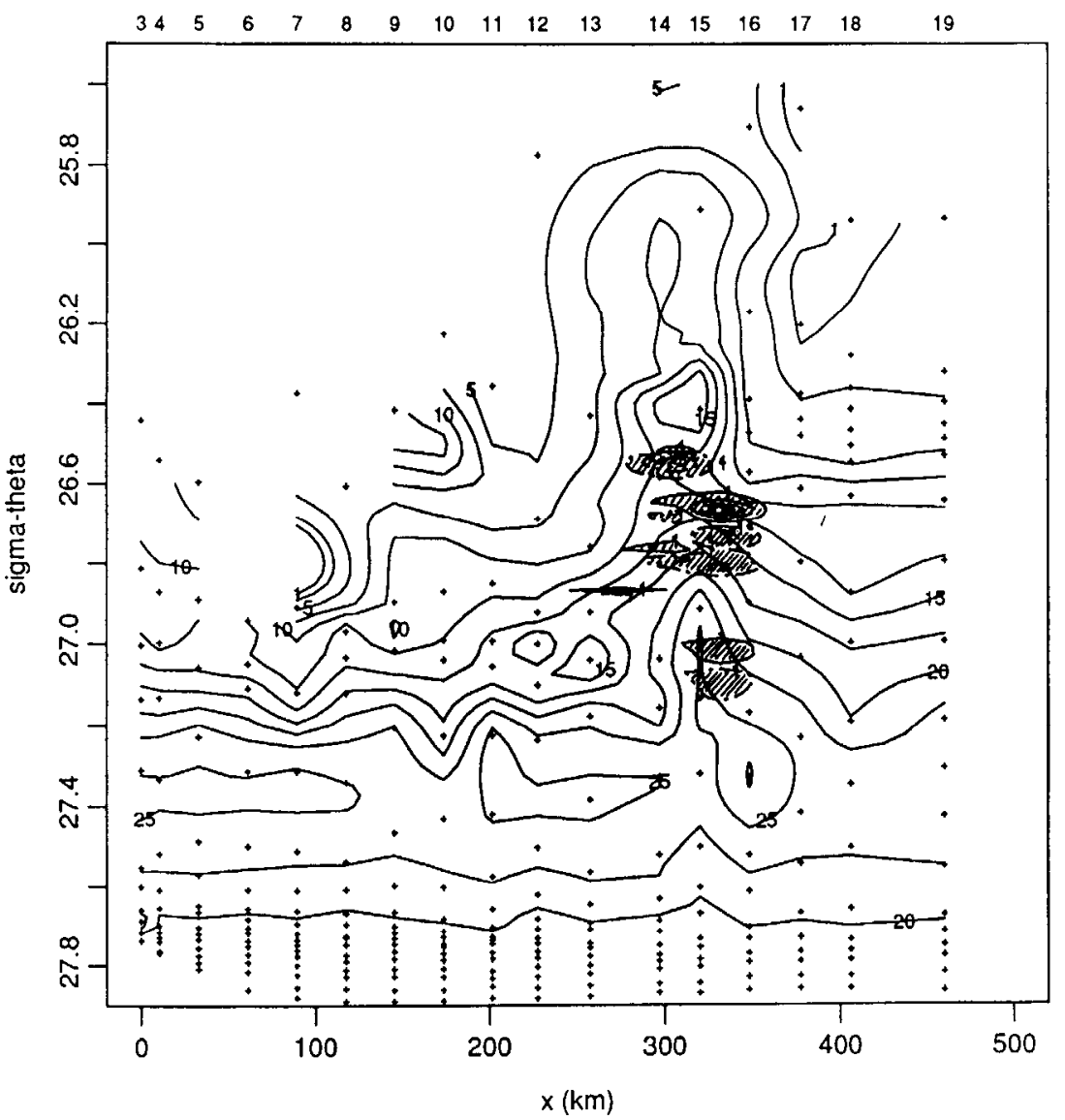

Fig. 7. (continued).

zontal, showing nutrient excess in the upper layers. We may also notice that the anomalies change considerably from one isopycnal to another, suggesting that they are produced by some vertically uneven mechanism. Over this figure we have overlayed the density tendency field (shaded regions). The $w_{\rho}$ distribution shows remarkable good agreement with the location of the nutrient anomalies. The inference is that negative density tendencies bring nutrient-rich waters to the shallow layers, while positive density tendencies bring nutrient-poor waters to deeper layers.

It should be noted, however, that downward transfer (i.e. negative anomalies) is not visible in Fig. 7(b), although it is suggested by the uneven character of the anomalies. There is no obvious answer for this. We believe, however, that the negative anomalies could be concealed by large nutrient-rich epipycnal taking place just before section $36^{\circ} \mathrm{N}$ was done. The idea of this inflow is based on Bower and Rossby's (1989) measurements of isopycnic trajectories between a trough and subsequent crest of a meander (away from the interior regime), combined with Csanady's (1989) idea of large correlation between layer depth and cross-stream velocity during this phase.

Still another hint pointing at the existence of significant diapycnal mixing during meanders comes from Coastal Zone Color Scanner (CZCS) images. Plate 1 consists of three CZCS images showing near-surface phytoplankton pigment concentrations (clorophyll a + pheotphytin a) in $\mathrm{mg} \mathrm{m}^{-3}$, for the southeastern U.S. continental shelf. The CZCS data were processed at the Center 


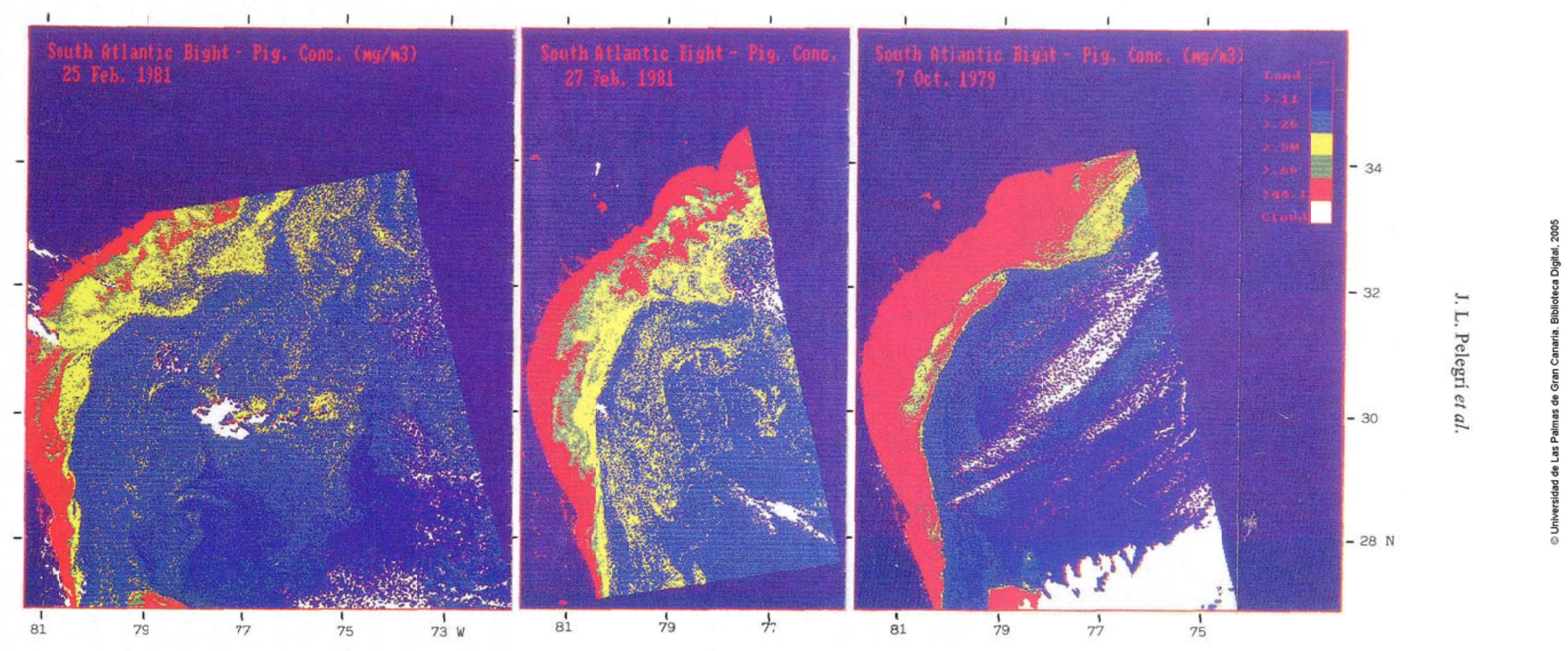

Plate 1. CZCS-derived near-surface pigment concentrations for the southeastern U.S. continental shelf: February 25, 1981 (left), February 27, 1981 (center), and October 7, 1979 (right). 
for Coastal Physical Oceanography, Old Dominion University, using an interactive satellite data analysis software package (PC-SEAPAK and Unix-SEAPAK) developed by NASA/GSFC (Darzi et al., 1989; Firestone et al., 1989). The pigment images were remapped to a standard Mercator projection, occupying a region from 26 to $36^{\circ} \mathrm{N}$ and from 75 to $81.5^{\circ} \mathrm{W}$, and registered to the coastline. The projection consisted of 512 by 512 pixels, the pixel resolution being $2 \mathrm{~km}$ $\times 2 \mathrm{~km}$.

For all images the same color palette is used. The pigment interval ranges are chosen such that the regions of intermediate pigment concentration (higher than Sargasso Sea waters but lower than the inner and middle shelf regions) are emphasized. The red color indicates pigment concentrations between 0.66 and $44.1 \mathrm{mg} \mathrm{m}^{3}$, which take place in the inner, middle and part of the outer shelf regions of the southeastern U.S. continental shelf. CZCS-derived pigment distributions in the Gulf Stream region show average concentrations between 0.05 and $0.2 \mathrm{mg}$ $\mathrm{m}^{-3}$ (blue tones), with maximum values of about $0.6 \mathrm{mg} \mathrm{m}^{3}$ represented by the yellow color. Comparisons with in situ data have shown that the CZCS-derived patterns are correct, although the calculated values usually underestimate several times the real pigment concentrations (Martins et al., 1995; see also Ishizaka et al., 1992).

The left and central images, corresponding to February 25 and 27 of 1981, show an anomalous situation in the pigment distribution, characterized by the presence of numerous scattered areas of relatively large biomass concentration (about $0.6 \mathrm{mg} \mathrm{m}^{3}$ ) in the central region of the Gulf Stream, its source unlikely related to shelf waters. This situation corresponds to the Gulf Stream distorted by steep meanders. The left image shows small, but rather steep meanders, in the region just north of the Straits of Florida, while the sequence from the left to the central image shows the growth of a large meander upstream of Charleston bump (note the very large offshore excursion from the crest to the trough of this meander). The extent of relatively large pigment concentrations in the central region of the Gulf Stream is rather abundant in the left image but it is even more impressive in the central image, particularly in the Gulf Stream region associated to the meander south of Charleston Bump. The right image, corresponding to October 7 of 1979, shows a typical situation of the Gulf Stream in the southeastern U.S. continental shelf, with less pronounced meanders and low pigment concentrations in its central waters.

One possible interpretation of these images comes from our discussion on the origin of diapycnal mixing in western boundary currents: in the event of steep meanders, nutricnt-rich upper-thermocline waters may reach the shallow waters through a rapid succession of mixing events taking place in several isopycnal layers. Each mixing event would probably occur at relatively small horizontal and vertical scales, and would transfer relatively small amounts of water and nutrients towards the surface. However, a sequence of these events would be important enough to transfer significant water mass and nutrients from the Nutrient Gulf Stream to the surface layers. These ideas are consistent with Pelegrí and Csanady (1991) results on two-way exchange between upper-thermocline and surface layers of the Gulf Stream. Pelegri and Csanady (1991) found two-way mean exchange of 2.4 Sv between the Florida Straits and section $36^{\circ} \mathrm{N}$, which would produce an upward net transfer of some $37 \mathrm{kmol} \mathrm{s}^{1}$ of nitrate. Such quantities would be large enough to maintain patchy productivity within the relatively sterile surface waters of the Gulf Stream.

\section{Conclusions}

The nutrient stream of the North Atlantic subtropical gyre, or Nutrient Gulf Stream, is responsible for the epipycnal transport of large amounts of nutrients to the northern North 
Atlantic. The Nutrient Gulf Stream has a prominent core on the 26.5-27.3 $\sigma_{\theta}$-band of the Gulf Stream system. In the northern regions, where the upper layers of this band outcrop (into the surface mixed-layer during summer), the core of the Nutrient Gulf Stream approaches the surface and its isopycnal extent is reduced to the lower portion of this band. The outcropping of these layers appears as the path through which the Nutrient Gulf Stream injects the nutrients necessary to maintain the spring bloom of the northern North Atlantic.

We may expect that western boundary currents of all oceans are the locus of nutrient streams. The reasons why other such regions show relatively little productivity, as compared with the North Atlantic, are probably of very diverse nature. Among the physical reasons we may suggest large surface stratification which prevents the outcrop of the nutrient stream layers (as in the North Pacific, e.g. Gargett, 1991), or the existence of currents which inhibit the poleward penetration of the nutrient stream (as the Antarctic Circumpolar Current in the Southern Atlantic). We believe that the ideas endorsed in this paper should only be a starting point for a much broader analysis of the importance of nutrient transport in western boundary currents, both in sustaining basin-wide productivity and in closing the global nutrient budget.

We have also endorsed the idea that diapycnal mixing in the Nutrient Gulf Stream is a likely mechanism for water exchange between nutrient-rich upper thermocline and nutrient-depleted surface layers, resulting in net mean nutrient transport towards the surface photic layers. We suggest that this is an intermittent process, related to shear-induced instabilities triggered during frontogenetical phases of the meanders, whose temporal and spatial repetition leads to two-way exchange between the upper thermocline and surface layers. This is likely to be a mechanism of prime importance in sustaining temporally and spatially patchy productivity (day-to-week, 10$100 \mathrm{~km}$ ) within the Gulf Stream itself.

\section{Acknowledgements}

We are grateful to $\mathrm{M}$. McCartney for kindly providing processed CTD and hydrographic data. Thanks are extensive to J. L. Reid for providing us with originals of Fig. 1, and to J. Arístegui for several useful comments. This work has been supported through a research grant from the Spanish government, CICYT's Grant AMB95-0731, and by the Universidad de Las Palmas de Gran Canaria and the Commonwealth Center for Coastal Physical Oceanography. Funding to produce Plate 1 was supplied through NASA's grant 106382. The hydrographic data used for Fig. 3 was collected with a grant from the USA Minerals Management Service.

\section{References}

Arnone, R. A., R. W. Nero, J. M. Jech and I. de Palma (1990): Acoustic imaging of biological and physical processes within Gulf Stream meanders. Eos Trans. Am. Geophys. Union, 71, 982.

Ashjian, C. J. (1993): Trends in copepod species abundances across and along a Gulf Stream meander: evidence for entrainment and detrainment of fluid parcels from the Gulf Stream. Deep-Sea Res., 40, 461-482.

Ashjian, C. J., S. L. Smith, C. N. Flagg, A. J. Mariano, W. J. Behrens and P. V. Z. Lane (1994): The influence of a Gulf Stream meander on the distribution of zooplankton biomass in the Slope Water, the Gulf Stream and the Sargasso Sea, described using a shipboard acoustic Doppler current profiler. Deep-Sea Res., 41, 23-50.

Atkinson, L. P., T. N. Lee, J. O. Blanton and G. Paffenhöfer (1987): Summer upwelling on the southeastern continental shelf of the U.S.A. during 1981. Hydrographic observations. Prog. Oceanogr., 19, 231-266.

Bolin, B., A. Bjorkstrom, K. Holmén and B. Moore (1983): The simultaneous use of tracers for ocean circulation studies. Tellus, 35, 206-236.

Bower, A. S. (1989): Potential vorticity balances and horizontal divergence along particle trajectories in Gulf Stream meanders east of Cape Hatteras. J. Phys. Oceanogr., 19, 1669-1681.

Bower, A. S. and T. Rossby (1989): Evidence of cross-frontal exchange processes in the Gulf Stream based on 
isopycnal RAFOS float data. J. Phys. Oceanogr., 19, 1177-1190.

Brewer, P. G. and D. Dyrssen (1987): Ocean chemical fluxes across $25^{\circ} \mathrm{N}$ in the Atlantic Ocean. Discussion paper at International GOFS Meeting, Paris, February 17-20, 25 pp.

Brown, O. B., R. H. Evans, J. W. Brown, R. H. Gordon, R. C. Smith and K. S. Baker (1984): Blooming off the U.S. East Coast: A satellite description. p. 67-84. In Global Ocean Flux Study, National Academy Press, Washington.

Brown, O., R. Evans, R. Watts, C. Casagrande, P. Hamilton, W. Boicourt and G. Csanady (1987): Study of Physical Processes on the U.S. Mid-Atlantic Continental Slope and Rise. Minerals Management Service Report No. 87$0024,506 \mathrm{pp}$.

Csanady, G. T. (1989): Energy dissipation and upwelling in a western boundary current. J. Phys. Oceanogr., 19, 462473.

Csanady, G. T. (1990): Physical basis of coastal productivity. The SEEP and MASAR experiments. Eos Trans. Am. Geophys. Union, 71, 1060-1065.

Csanady, G. T. and P. Hamilton (1988): Circulation of slopewater. Cont. Shelf Res., 8, 565-624.

Darzi, M., J. Chen, J. K. Firestone and C. R. McClain (1989): SEAPAK: A satellite image analysis system for oceanographic research. Preprint Volume, 5th International Conference on Interactive and Information Processing Systems for Meteorology, Oceanography and Hydrology, American Meteorological Society, Boston, Massachusetts, pp. 26-32.

Esaias, W. E., G. C. Feldman, C. R. McClain and J. A. Elrod (1986): Monthly satellite-derived phytoplankton pigment distribution for the North Atlantic basin. Eos Trans. Am. Geophys. Union, 67, 835-837.

Firestone, J. K., G. Fu, J. Chen, M. Darzi and C. R. McClain (1989): PC-SEAPAK: A state-of-the-art image display and analysis system for NASA's oceanographic research program. Preprint Volume, 5th International Conference on Interactive and Information Processing Systems for Meteorology, Oceanography and Hydrology, American Meteorological Society, Boston, Massachusetts, pp. 33-40.

Flierl, G. R. and C. S. Davis (1993): Biological effects of Gulf Stream meandering. J. Mar. Res., 51, 529-560.

Gargett, A. E. (1991): Physical processes and the maintenance of nutrient-rich euphotic zones. Limnol. Oceanogr., 36, $1527-1545$.

Garside, C. and J. C. Garside (1993): The "f-ratio" on $20^{\circ} \mathrm{W}$ during the North Atlantic Bloom Experiment. DeepSea Res., 40, 75-90.

Hitchcock, G. L., A. J. Mariano and T. Rossby (1993): Mesoscale pigment fields in the Gulf Stream: Observations in a meander crest and trough. $J$. Geophys. Res., 98, 8425-8445.

Ishizaka, J., H. Fukushima, M. Kishino, T. Kishino, T. Saino and M. Takahashi (1992): Phytoplankton pigment distributions in regional upwelling around the lzu Peninsula detected by Coastal Zone Color Scanner on May 1982. J. Oceanogr., 48, 305-327.

Jenkins, W. J. (1980): Tritium and ${ }^{3} \mathrm{He}$ in the Sargasso Sea. J. Mar. Res., 38, 533-569.

Jenkins, W. J. (1987): ${ }^{3} \mathrm{H}$ and ${ }^{3} \mathrm{He}$ in the Beta Triangle: observations of gyre ventilation and oxygen utilization rates. J. Phys. Oceanogr., 17, 763-783.

Kawase, M. and J. L. Sarmiento (1985): Nutrients in the Atlantic thermocline. J. Geophys. Res., 90, 8961-8979.

Kirwan, A. D. (1963): Circulation of Antarctic Intermediate Water Deduced through Isentropic Analysis. Reference 63-34F, Texas A \& M University, College Station, Texas, 34 pp.

Leetma, A. and A. F. Bunker (1978): Updated charts of the mean annual wind stress, convergences in the Ekman layers, and Sverdrup transports in the North Atlantic. J. Mar. Res., 36, 311-322.

Levitus, S. (1982): Climatological Atlas of the World Ocean. NOAA Professional Paper 13, U.S. Government Printing Office, Washington, D.C.

Lohrenz, S. E., J. J. Cullen, D. A. Phinney, D. B. Olson and C. S. Yentsch (1993): Distributions of pigments and primary production in a Gulf Stream meander. J. Geophys. Res., 98, 14545-14560.

Luyten, J. and H. Stommel (1986): Gyres driven by combined wind and buoyancy flux. J. Phys. Oceanogr., 16, 15511560 .

Luyten, J., J. Pedlosky and H. Stommel (1983): The ventilated thermocline. J. Phys. Oceanogr., 13, 292-309.

Marra, J. and C. Ho (1993): Initiation of the spring bloom in the northeast Atlantic $\left(47^{\circ} \mathrm{N}, 20^{\circ} \mathrm{W}\right)$ : a numerical simulation. Deep-Sea Res., 40, 55-73.

Martin, J. H., G. A. Knauser, D. M. Karl and W. W. Broenkow (1987): VERTEX: carbon cycling in the northwest Pacific. Deep-Sea Res., 34, 267-285.

Martins, A. M., E. E. Hofmann and C. R. McClain (1995): CZCS-derived pigment data for the southeastern U.S. continental shelf from 1978 to 1986 (October to May). Part III: Atmospheric correction, pigment time series, 
and comparison with in situ data. Old Dominion University Research Foundation Report No. 95-06, $299 \mathrm{pp}$.

Montgomery, R. B. (1937): A suggested method for representing gradient flow in isentropic surfaces. Bull. Am. Meteorol. Soc., 18, 210-212.

Montgomery, R. B. (1938): Circulation in upper layers of Southern North Atlantic deduced with use of isentropic analysis. Papers Phys. Oceanogr. Meteorol., 6, 1-55.

Munk, W. H. (1950): On the wind-driven ocean circulation. J. Meteorol., 7, 79-93.

Newton, C. W. (1978): Fronts and wave disturbances in Gulf Stream and atmospheric jet stream. J. Geophys. Res., 83, 4697-4706.

Nurser, A. J. G. and J. C. Marshall (1991): On the relationship between subduction rates and diabatic forcing of the mixed layer. J. Phys. Oceanogr., 21, 1793-1802.

Pelegrí, J. L. and G. T. Csanady (1991): Nutrient transport and mixing in the Gulf Stream.J. Geophys. Res., 96, 25772583.

Pelegrí, J. L. and G. T. Csanady (1994): Diapycnal mixing in western boundary currents. J. Geophys. Res., 99, 1827518304.

Redfield, A. C. (1936): An ecological aspect of the Gulf Stream. Nature, 138, 1013.

Reid, J. L. (1965): Intermediate Waters of the Pacific Ocean, Vol. 2. The Johns Hopkins Oceanographic Studies, John Hopkins University Press, Baltimore, $85 \mathrm{pp}$.

Reid, J. L. (1981) On the mid-depth circulation of the world ocean. p. 70-111. In Evolution of Physical Oceanography, ed. by B. A. Warren, MIT Press, Cambridge.

Reid, J. L. (1994): On the total geostrophic circulation of the North Atlantic Ocean: Flow patterns, tracers, and transports. Prog. Oceanogr., 33, 1-92.

Rhines, P. B. and W. Y. Young (1982): A theory of wind-driven circulation. I. Mid-ocean gyres. J. Mar. Res., 40, 559-596.

Richards, A. F. and A. C. Redfield (1955): Oxygen-density relationships in the western North Atlantic. Deep-Sea Res., 2, 182-199.

Richardson, P. L. (1983): Eddy kinetic energy in the North Atlantic from surface drifters. J. Geophys. Res., 88, $4355-$ 4367.

Riley, G. A. (1951): Oxygen, phosphate and nitrate in the Atlantic Ocean. Bull. Bingham Oceanogr. Collection, 13, $1-125$.

Rintoul, S. R. and C. Wunsch (1991): Mass, heat, oxygen and nutrient fluxes and budgets in the North Atlantic Ocean. Deep-Sea Res., 38, Suppl. 1, S619-S644.

Roemmich, D. and C. Wunsch (1985): Two transatlantic sections: meridional circulation and heat flux in the subtropical North Atlantic Ocean. Deep-Sea Res., 32, 619-644.

Rossby, C. G. (1936): Dynamics of steady ocean currents in the light of experimental fluid mechanics. Papers Phys. Oceanogr. Meteorol., 5, 1-43.

Sarmiento, J. L. (1983): A tritium box model of the North Atlantic thermocline. J. Phys. Oceanogr., 13, 1269-1274.

Sarmiento, J. L., C. G. Rooth and W. Roether (1982): The North Atlantic tritium distribution in 1972. J. Geophys. Res., 87, 8047-8056.

Sarmiento, J. L., G. Thiele, R. M. Key and W. S. Moore (1990): Oxygen and nitrate new production and remineralization in the North Atlantic subtropical gyre. J. Geophys. Res., 95, 18303-18315.

Schlitzer, R. (1988): Modeling the nutrient and carbon cycles of the North Atlantic. 1. Circulation, mixing coefficients and heat fluxes. J. Geophys. Res., 93, 10699-10723.

Schlitzer, R. (1989): Modeling the nutrient and carbon cycles of the North Atlantic. 2. New production, particle fluxes, $\mathrm{CO}_{2}$ gas exchange, and the role of organic nutrients. J. Geophys. Res., 94, 12781-12794.

Smith, L. T., D. B. Boudra and R. Bleck (1990): A wind-driven isopycnic coordinate model of the North and Equatorial Atlantic Ocean. 2. The Atlantic Basin experiments. J. Geophys. Res., 95, 13105-13128.

Stefánsson, U. and L. P. Atkinson (1971): Nutrient-density relationships in the western North Atlantic between Cape Lookout and Bermuda. Limnol. Oceanogr., 16, 51-59.

Stommel, H. (1979): Determination of water mass properties of water pumped down from the Ekman layer to the geostrophic flow below. Proc. Natl. Acad. Sci. USA, 76, 3051-3055.

Talley, L. D. and M. S. McCartney (1982): Distribution and circulation of Labrador Sea Water. J. Phys. Oceanogr., 12, 1189-1205.

Thiele, G. and J. L. Sarmiento (1990): Tracer dating and ocean ventilation, J. Geophys. Res., 95, 9377-9391.

Tsuchiya, M. (1968): Upper Waters of the Intertropical Pacific Ocean, Vol. 4. The Johns Hopkins Oceanographic Studies, Johns Hopkins University Press, Baltimore, $50 \mathrm{pp}$. 
Veronis, G. (1988): Circulation driven by winds and surface cooling. J. Phys. Oceanogr., 18, 1920-1932.

Worthington, L. V. (1976): On the North Atlantic Circulation, Vol. 6. The Johns Hopkins Oceanographic Studies, Johns Hopkins University Press, Baltimore, $110 \mathrm{pp}$.

Yentsch, C. S. (1974): The influence of geostrophy on primary production. Thetys, 6, 111-118.

Yoder, J. A., L. A. Atkinson, S. S. Bishop, E. E. Hofmann and T. N. Lee (1983): Effect of upwelling on phytoplankton productivity of the outer southeastern United States continental shelf. Cont. Shelf Res., 1, 385-404. 